\title{
The Role of Anchoring Bias in the Equity Market: Evidence from Analysts' Earnings Forecasts and Stock Returns ${ }^{\dagger}$
}

\author{
Ling Cen \\ Joseph L. Rotman School of \\ Management \\ University of Toronto \\ ling.cen@ rotman.utoronto.ca \\ (1) 4169783119
}

\author{
Gilles Hilary \\ Department of Accounting \\ INSEAD \\ gilles.hilary@insead.edu \\ (33) 160729233
}

\author{
K.C. John Wei \\ Department of Finance \\ Hong Kong University of \\ Science and Technology \\ johnwei@ust.hk
} (852) 23587676

This Draft: October 15, 2010

\begin{abstract}
$\dagger$ A previous draft of this paper was circulated under the title: "The Cross-Sectional Anchoring of Forecasted Earnings per Share and Expected Stock Returns." We appreciate the helpful comments from Kee-Hong Bae, Kalok Chan, Louis Chan, Eric Chang, Xin Chang, Sudipto Dasgupta, Ming Dong, John Doukas, Jie Gan, Robin Greenwood, Lu Hai, David Lesmond, Cynthia Pan, Kevin Wang, Chishen Wei, Jeffrey Wurgler, Chu Zhang, and seminar participants at the HEC Paris, the Hong Kong University of Science and Technology, National Chiao-Tung University, National Taiwan University, National Sun Yat-sen University, Peking University, York University, the 2008 Chinese International Conference in Finance, the 2008 European Finance Association annual meeting, and the 2007 Financial Management Association meetings. We specially appreciate Jie Zhang for his constructive and insightful comments and suggestions. The authors also thank Alice Cheung for editorial assistance. John Wei acknowledges financial support from Research Project Competition Grant from Hong Kong University of Science and Technology (RPC10BM08).
\end{abstract}

Corresponding author: K.C. John Wei, Department of Finance, Hong Kong University of Science and Technology, Clear Water Bay, Kowloon, Hong Kong. Tel: (852)-2358-7676; Fax: (852)-2358-1749. Email: johnwei@ust.hk. 
The Role of Anchoring Bias in the Equity Market: Evidence from Analysts' Earnings Forecasts and Stock Returns

\begin{abstract}
Anchoring" describes the fact that in forming numerical estimates of uncertain quantities, adjustments in assessments away from an arbitrary initial value are often insufficient. We show that this cognitive bias has significant economic consequences for the efficiency of financial markets. We find that analysts make optimistic (pessimistic) forecasts when a firm's forecast earnings per share (FEPS) is lower (higher) than the industry median. Further, firms with FEPS greater (lower) than the industry median experience abnormally high (low) future stock returns, particularly around subsequent earnings announcement dates. Firms with a high FEPS relative to the industry median are also more likely to engage in stock splits. Finally, split firms experience greater positive forecast revisions, larger forecast errors, and larger negative earnings surprises after a stock split compared to which did not split their stocks, especially for firms with a low FEPS relative to the industry median.
\end{abstract}

Key words: Anchoring, Cognitive biases, Analysts' earnings forecasts, Cross-sectional stock returns

JEL Classification: G14, G17 


\section{Introduction}

Analysts are key financial market participants. Researchers often use analysts' earnings forecasts as proxies for market expectations and differences in opinions. In addition, analysts' earnings forecasts are one of the rare settings for which researchers have a large natural data set of individual analysts' actual decisions, and for which the biases in decision making can be observed and verified ex-post. Not surprisingly, the activities of analysts have been a fertile ground for behavioral research. Prior studies have shown that analysts often suffer from a number of biases. However, the implications of these potential cognitive biases for investors and, even more so for managers, are less understood.

This study considers the behavior of financial market participants from a perspective different from that of previous research. It focuses on anchoring bias, a topic that has been characterized by Hirshleifer (2001) as an important part of "dynamic psychology-based assetpricing theory in its infancy" (p. 1535). "Anchoring" describes the fact that, in forming numerical estimates of uncertain quantities, adjustments in assessments away from some initial value are often insufficient. One of the first studies of this cognitive bias is the seminal experiment by Kahneman and Tversky (1974). These authors report that estimates of an uncertain proportion (the percentage of African nations in the United Nations) were affected by a number between 0 and 100 that was determined by spinning a wheel of fortune in the subjects' presence. Subsequent research (reviewed in Section II) has confirmed the generality and the robustness of this cognitive bias.

We hypothesize that market participants such as sell-side analysts and investors may also be affected by such anchoring bias when they estimate the future profitability of a firm. This estimation is a complex task that involves a high degree of uncertainty. This suggests that market 
participants may anchor on salient but irrelevant information. In particular, our discussions with financial analysts suggest that earnings forecasts of a specific firm are likely to be affected by the levels of forecasted EPS of its industry peers. One analyst pointed out in an interview that analysts "are reluctant to make earnings forecasts that further deviate from the current industry 'norm' (i.e., a historically stable range of forecasted EPS within the industry)." Specifically, when a company's current forecasted EPS level has already been much higher (lower) than those of its industry peers, analysts appear to make insufficient upward (downward) adjustments even if the forecast revisions are well supported by fundamental information. We describe this observation as the analysts' anchoring bias towards its industry norm. To capture this intuition, we construct a measure of cross-sectional anchoring in forecasted EPS (FEPS) as the difference between the firm's FEPS (F-FEPS) and the industry median FEPS (I-FEPS), scaled by the absolute value of the latter. With this measure of cross-sectional anchoring (named $C A F$ hereafter), we generate the following hypotheses.

First, if analysts anchor on the industry norm, their forecasts should be too close to this number. As a consequence, analysts are likely to underestimate (overestimate) the future earnings of firms with their forecast earnings per share (F-FEPS) above (below) the I-FEPS. In other words, analysts give more pessimistic earnings forecasts for firms with a high FEPS (i.e., firms with F-FEPS above I-FEPS) than for similar firms in the same industry with a low FEPS (i.e.; firms with F-FEPS below I-FEPS). Therefore, earnings forecast errors should be lower for high FEPS firms than for low FEPS firms in the same industry. ${ }^{1}$

\footnotetext{
${ }^{1}$ We define forecast errors as (Forecasted EPS - Actual EPS) / IActual EPSI. All our results hold if the forecast errors are alternatively defined as (Forecasted EPS - Actual EPS) / Price.
} 
If investors are affected by biased analysts' earnings forecasts, investors' expectations of a firm's future profitability should be similarly biased. Firms with a high FEPS compared to their industry peers should suffer from low expectations regarding their future profits. Conversely, firms with a low FEPS relative to their industry peers should enjoy unduly high expectations regarding their future profits. If this is the case, stocks with high levels of EPS forecasts should significantly outperform similar stocks in the same industry with low levels of EPS forecasts when the firm's true profitability is subsequently revealed, for example, around subsequent earnings announcement dates.

We generate empirical results consistent with all the hypotheses suggested by crosssectional anchoring. Using U.S. data from 1983 to 2005, we find that analysts' earnings forecasts for firms with a high $C A F$ are more pessimistic than the forecasts on similar firms with a low $C A F$. This result is consistent with analysts anchoring their forecasts on the industry median. We further find that stock returns are significantly higher for firms with a high $C A F$ than for similar firms in the same industry with a low $C A F$. The positive relationship between firm $C A F$ and future stock returns cannot be explained by known risk factors, book-to-market ratios, earningsto-price ratios, fundamental value-to-price ratios, accounting accruals, price momentum, earnings momentum, or the nominal price per share. Moreover, earnings surprises are relatively more positive for firms with a high $C A F$ than for firms with a low $C A F$. These results are consistent with the notion that investors are also affected by the cross-sectional anchoring bias. All these results are stronger when the industry norm is more stable and when market participants are less sophisticated. We also find that the likelihood of a stock split within a year is greater when the $C A F$ is high. This is consistent with the idea that managers realize the existence of anchoring in the financial markets and adjust their behavior to cater to this cognitive bias. 
Finally, firms with a low $C A F$ experience more positive revisions in earnings forecasts and more positive forecast errors after a stock split relative to no-split firms than do firms with a high $C A F$. Consequently, firms with a low $C A F$ experience more negative changes in earnings surprises relative to no-split firms after a stock split than do firms with a high $C A F$. Results are robust to controlling for alternative anchors. For example, in addition to anchoring on the industry norm, it is also possible that analysts and investors may anchor on the most recently announced earnings. Although we find that analysts and investors also anchor on the most recently announced earnings, our key results hold even after controlling for this effect. In fact, we find that both cross-sectional and time-series anchoring biases affect financial markets; but the former is more influential than the latter.

These results confirm that anchoring, an important cognitive bias in the psychology literature, affects decision making by individuals in an important economic setting. This large sample test complements the previous research that was largely based on small sample experimental work. To the best of our knowledge, this study is the first one to use a large sample archival approach to understand the implications of the cross-sectional anchoring effect in a finance setting. Although we focus on analysts' earnings forecasts and price behavior in order to take advantage of a particularly rich data set, we expect that our results can be generalized in other settings as well. The results of this study also enhance our understanding of the financial markets by providing new understanding of analyst and investor behavior. Of particular importance, the results suggest that understanding this cognitive bias may yield a trading strategy that generates abnormal returns. Specifically, our results suggest that a hedge portfolio that goes long on firms with a high $C A F$ and short on firms with a low $C A F$ could, over the period studied, 
have generated a monthly risk-adjusted return (alpha) of $0.76 \%$, or $9.12 \%$ per year. ${ }^{2}$ The profitability of such a trading strategy remains significant for investment horizons that extend to at least 12 months. Finally, our results suggest a corporate strategy based on stock splits for managers of firms with a high level of FEPS. Such a strategy can mitigate under-valuation and sometimes generate over-valuation by influencing analysts' earnings forecasts or revisions.

In addition, our study complements previous studies on nominal stock prices. Benartzi et al. (2007) find that the cross-sectional distribution of nominal stock prices per share in the United States has been very stable with the median hovering around $\$ 30$ since early in the last century. We show that a similar effect exists for forecasted EPS: the median nominal FEPS has been hovering between $\$ 1.50$ and $\$ 2.00$ (shown in Figure 2) since analysts' earnings forecasts became available in 1978. Baker, Greenwood, and Wurgler (2009) suggest that managers split shares to cater to investors' preference driven by "small-cap premiums." However, the source of this higher valuation for low-price firms remains unclear. We consider the possibility that these firms are overvalued because of the anchoring bias of market participants. Consistent with this view, our results suggest that low FEPS stocks (relative to their industry peers) are indeed overpriced.

The remainder of this study is organized as follows. In Sections II, we review the previous studies on anchoring bias. In Section III, we develop our research hypotheses. In Section IV, we describe our research design. Section V discusses our sample and descriptive statistics, while Section VI presents our main empirical results. Section VII presents a few robustness checks and we conclude the study in Section VIII.

\footnotetext{
${ }^{2}$ A similar trading strategy based on time-series anchoring generates trading profits that are only one-third of those generated from cross-sectional anchoring.
} 


\section{Prior Research on Anchoring}

The results of prior research (Kahneman and Tversky (1974)) suggest that individuals use cognitively tractable decision strategies, known as heuristics, to cope with complex and uncertain situations. These heuristics reduce complex inference tasks to relatively simple cognitive operations. Although these "mental short-cuts" help individuals in dealing with complex and uncertain situations, they may also lead to systematically skewed outcomes. The anchoring effect is one of the most studied cognitive biases that lead individuals to make sub-optimal decisions. In their classic study, Kahneman and Tvesky (1974) explore the idea that individuals frequently form estimates by starting with an easily available reference value and then adjusting from this value. Although this approach may not be problematic per se, research has shown that individuals typically fail to properly adjust their final estimates away from the salient but overemphasized starting point (the "anchor").

Kahneman and Tversky's (1974) seminal example involves spinning a wheel-of-fortune in front of the subjects and thus generating a number between 0 and 100. They asked the subjects for their best estimates of the percentage of African nations in the United Nations. The obviously irrelevant random number generated from the wheel-of-fortune generates systematic bias in the estimations. For example, the average estimate from subjects who observed the number 10 was $25 \%$. In contrast, the average estimate from subjects who observed the number 65 was $45 \%$. This result has been replicated in many other experimental settings. For example, Kahneman and Tversky (1974) asked half of their subjects to estimate the value of $1 \times 2 \times 3 \times 4 \times 5 \times 6 \times 7 \times 8$ and asked the other half to estimate the value of $8 \times 7 \times 6 \times 5 \times 4 \times 3 \times 2 \times 1$. The average answers from the two groups were 512 and 2,250, respectively. Russo and Shoemaker (1989) provide an anchor based on a constant (varying from 400 to 1,200 ) plus the last three digits of the subject's phone 
number. The two researchers then asked for an estimate of the year in which the Attila the Hun was finally defeated. Estimates were positively and significantly correlated with the anchor. More recently, Qu, Zhou, and Luo (2008) provide physiological evidence of the anchoring process based on event-related potential techniques (i.e., techniques that measure the brain responses stimulated by a thought or a perception).

Research has shown that anchoring influences various types of decisions in many different contexts. These include judicial sentencing decisions (Englich and Mussweiler, (2001)), personal injury verdicts (Chapman and Bornstein (1996)), estimation of the likelihood of diseases (Brewer, Chapman, Schwartz, and Bergus (2007)), job performance evaluation (Latham, Budworth, Yanar, and Whyte (2008)), judges' rankings in competitions (Ginsburgh and van Ours (2003)), and real estate acquisitions (Northcraft and Neale (1987)). ${ }^{3}$

Previous research has also suggested that it is particularly difficult to correct anchoring bias. Consistent with this view, Northcraft and Neale (1987) conclude (p. 95) that "(1) experts are susceptible to decision bias, even in the confines of their 'home' decision setting, and (2) experts are less likely than amateurs to admit to (or perhaps understand) their use of heuristics in producing biased judgments." Plous (1989) shows that task familiarity is not sufficient to avoid anchoring bias and that the effects of anchoring bias are not significantly influenced by the ease

\footnotetext{
${ }^{3}$ In addition, anchoring has been shown to influence intuitive numerical estimations (Wilson, Houston, Etling, and Brekke (1996)), probability estimates (Plous (1989)), estimations of sample means and standard deviations (Lovie (1985)) and estimates of confidence intervals (Block and Harper (1991)), sales predictions (Hogarth (1980)), Bayesian updating tasks (Lopes (1981)), utility assessments (Johnson and Schkade (1989)), risk assessments (Lichtenstein, Slovic, Fischhoff, Layman, and Combs (1978)), preferences of gambles (Lichtenstein and Slovic (1971)), perception of deception and information leakage (Zuckerman, Koetsner, Colella, and Alton (1984)), negotiation outcomes (Ritov (1996)), and choices between product categories (Davis, Hoch and Ragsdale (1986)).
} 
with which respondents can imagine the outcome (outcome availability), by the instructions to list the most likely path to the outcome (path availability), or by casting the problem in terms of avoidance (rather than occurrence). Plous (1989) also mentions that anchoring bias exists even after correcting for various social demand biases (i.e., the existence of expert opinion running against the initial anchor). Wright and Anderson (1989) consider the effect of situation familiarity on anchoring. They conclude (p. 68) that, "The anchoring effect is so dominant that increasing situational familiarity did not result in decreased anchoring." They find that monetary incentives can reduce anchoring, but the effect is only marginal in its statistical significance. In contrast, Tversky and Kahneman (1974) find that payoffs for accuracy do not reduce the anchoring effect. Further, Brewer, Chapman, Schwartz, and Bergus (2007) report that accountability does not reduce anchoring bias in doctors' predictions of infection. Whyte and Sebenius (1997) provide results suggesting that groups do not de-bias individual judgments.

The amount of research on the anchoring bias in financial markets is very limited. DeGeorge, Patel, and Zeckhauser (1999) suggest that executives aim to exceed salient EPS thresholds. George and Hwang (2004) propose that investors are reluctant to bid the price high enough when a stock price is at or near its highest historical value. Consistent with this intuition, they find that a stock price near its 52-week high has predictive power for future stock returns. Campbell and Sharpe (2009) show that professional forecasters anchor their predictions of macroeconomic data such as the consumer price index or non-farm payroll employment on previous values, which leads to systematic and sizeable forecast errors. Baker, Pan, and Wurgler (2009) suggest that anchoring bias also affects corporate acquisitions. However, these studies focus on time-series (i.e., historical information of the firm itself) anchoring bias. In contrast, we focus on the effect of cross-sectional (i.e., contemporaneous information of other firms) 
anchoring, a topic that has not been explored by the prior research, although we also consider time-series anchoring of most recent announced earnings.

\section{Hypotheses Development}

Given the documented robustness of anchoring bias, we hypothesize that market participants such as sell-side analysts and investors should also be affected by anchoring heuristics when they estimate the future profitability of a firm. This estimation is a complex task that involves a high degree of uncertainty, which makes market participants naturally anchor on salient information in their decision making. Prior research (Chapman and Johnson (2002)) suggests that anchors are most influential if they are expressed on the same response scale as the items being estimated (i.e., dollars for dollars rather than dollars when estimating percentage) and if they represent the same underlying dimension (width for width rather than width when estimating length). The popular financial website, Investopedia.com, notes that, "Earnings per share is generally considered to be the single most important variable in determining a share's price."4 Tversky and Kahneman (1974) show in an experimental setting that subjects priced with the median of other subjects' estimates anchor on this median. A natural candidate for possible anchors in our setting is thus the industry median forecast earnings per share. ${ }^{5}$ Since an analyst usually covers a group of firms within the same industry, this number is readily available and is

\footnotetext{
${ }^{4}$ http://www.investopedia.com/terms/e/eps.asp.

${ }^{5}$ We do not argue here that the industry median FEPS is the only possible anchor that leads to behavioral bias. Instead, we argue that it is an important one, particularly in explaining the empirical patterns documented in this study. We will discuss alternative anchors including time-series anchoring in Section 7.2.
} 
naturally associated with the task at hand. For example, Zacks Investment Research states in the first line of a recent analyst report that, "Median EPS is projected to drop 21.2\%.",

To validate the plausibility of industry median forecasted EPS as an anchor, we interviewed six stock analysts from leading investment banks. First, we described two hypothetical stocks, stock A and stock B, with identical business and firm characteristics (such as firm size, firm performance, market power, corporate governance structure, and so forth). Second, we told our interviewees that the only differences between stock A and stock B were the level of earnings per share (EPS) and the number of shares outstanding: stock A has an EPS of \$0.1 with 100,000 shares outstanding and stock B has an EPS of $\$ 10$ with 1,000 shares outstanding. Third, we showed our interviewees a hypothetical figure of the industry crosssectional distribution of forecast EPS (similar to Figure 2 in our study) with the industry median forecasted EPS hovering around $\$ 1.5$. Finally, we asked them which of the stocks is more likely to double its earnings per share next year (i.e., from $\$ 0.1$ to $\$ 0.2$ per share for stock A, and from $\$ 10$ to $\$ 20$ per share for stock B). Five out of six interviewed analysts picked Stock A. When we asked them which stock is more likely to halve its earnings per share next year (i.e., from $\$ 0.1$ to $\$ 0.05$ per share for stock $A$, and from $\$ 10$ to $\$ 5$ per share for stock $B)$, these five analysts chose stock B instead. In a follow-up discussion, analysts suggested that their estimations were obviously affected by the industry 'norm' of the forecast EPS, especially when it is stable over time.

If participants indeed anchor on the industry median FEPS (i.e., cross-sectional anchoring), this should have important implications for the behavior of analysts, investors and the managers of publicly traded companies. First, if analysts anchor on the industry median

\footnotetext{
${ }^{6}$ http://www.reuters.com/article/pressRelease/idUS213655+25-Jun-2009+BW20090625.
} 
forecasted EPS (I-FEPS), their forecasts should be too close to this number. As a consequence, they would underestimate the future earnings growth of firms with high FEPS (relative to the industry median). In other words, analysts should give more optimistic earnings forecasts for firms with low FEPS (relative to the industry median) than for similar firms in the same industry with high FEPS (relative to the industry median). Thus, signed earnings forecast errors would be larger for low FEPS firms than for high FEPS firms in the same industry. This motivates our first hypothesis:

H1: Analyst forecasts are more optimistic (indicated by a higher signed forecast errors in our study) for firms with a low FEPS relative to their industry median FEPS than for firms with a high FEPS relative to their industry median FEPS.

If investors are affected by biased analysts' earnings forecasts, their expectations of future profitability should also be biased. Firms with high FEPS relative to their industry median should suffer from low expectations regarding their future profits. Conversely, firms with low FEPS relative to their industry median should enjoy unduly high expectations regarding their future profits. If this is the case, stocks with high FEPS should significantly outperform similar stocks in the same industry with low FEPS once the true profitability is revealed. This motivates our second hypothesis:

H2: Controlling for risk factors, future stock returns for firms with high FEPS relative to their industry median FEPS are higher than for firms with low FEPS relative to their industry median FEPS. 
This prediction should be particularly true around subsequent earnings announcement dates.

If managers expect such biases among analysts and investors, they may be tempted to manage their EPS forecasts so that they are low relative to other similar firms. One natural way to achieve this would be to split the stock. We expect that firms with a high FEPS relative to other firms in the industry would be more likely to engage in stock splits to lower their FEPS. ${ }^{7}$ This motivates our third hypothesis:

H3: The probability of a stock split is higher for firms with a high FEPS relative to their industry median FEPS than for firms with a low FEPS relative to their industry median.

If this strategy is successful, both analysts and investors would be affected. In particular, split firms should, on average, experience larger positive revisions in their earnings forecasts, greater positive forecast errors, and larger negative changes in earnings surprises after a stock split than no-split firms, especially for firms with a low initial FEPS relative to the industry.

\section{The Research Design}

We apply two basic approaches to test our hypotheses: regression analyses and portfolio sorts. The regression approach allows us to control easily for a host of potentially confounding effects. The portfolio approach allows us to address econometric issues such as overlapping

\footnotetext{
${ }^{7}$ The idea here is similar to the catering theory of share prices suggested and demonstrated by Baker, Greenwood, and Wurgler (2009). However, our tests of anchoring bias in stock splits mainly focus on analysts' response instead of the impact on investors.
} 
observations and non-linearities more easily than in a regression framework. The portfolio approach also allows us to deal more easily with the "bad model issue" discussed by Fama (1998) and Mitchell and Stafford (2000).

\section{A. Regression analysis}

The following cross-sectional and time-series model is used to test our hypotheses:

$$
\operatorname{Dep}_{\operatorname{Var}_{i, t}}=\alpha+\beta C A F_{i, t-1}+\gamma^{K} X_{i, t-1}^{K}+\varepsilon_{i, t},
$$

where DepVar ${ }_{i, t}$ represents the value of the dependent variable for firm $i$ in period $t$. To test our first hypothesis, analysts' forecast error $(F E)$ is the dependent variable. $F E$ is the difference between the consensus EPS forecast and the actual EPS announced after the end of the fiscal year, scaled by the absolute value of the latter. The consensus EPS forecast is the mean of oneyear-ahead EPS forecast in the previous month from the Institutional Brokers' Estimate System (I/B/E/S) unadjusted summary historical file. The actual EPS is reported in the I/B/E/S actual file.

To test the second hypothesis, two dependent variables are evaluated at the end of each calendar month, $t$. The first is $B H A R_{0: 1}$, defined as the cumulative buy-and-hold raw return for firm $i$ in the current month, $t^{8}$ The second is ECAR, defined as the sum of the three-day, riskadjusted, cumulative abnormal returns around the earnings announcements over the next twelve months after the end of calendar month $t-1$.

\footnotetext{
${ }^{8}$ We focus on a one-month horizon to minimize the bad model problem discussed by Fama (1998) and Mitchell and Strafford (2000). As discussed in Section 6, the results hold if we extend the horizon to twelve months.
} 
The main treatment variable, $C A F$, measures cross-sectional anchoring bias. $C A F_{i, t-1}$ is defined as the difference between the FEPS for firm $i(F-F E P S)$ in month $t-1$ and the industry median FEPS (I-FEPS) in the same month, scaled by the absolute value of the latter. We define 48 industries following the approach of Fama and French (1997). Various other $C A F$ specifications and industry definitions are tested, but the results remain quantitatively and qualitatively similar. ${ }^{9}$ These results are not presented here but are available upon request. Two interesting features of this variable is that the firm can choose its preferred value of $C A F$ through stock split (and reverse stock splits) but also that a firm can affect the value of $C A F$ for other firms in the same industry by engaging in a stock split. ${ }^{10}$ The fact that economically irrelevant decisions affect the value of $C A F$ and make it an arbitrary number mitigates the risk that $C A F$ proxies for some omitted constructs such as a risk factor.

Aside from including an (untabulated) constant, a vector of $K$ control variables $\left(X^{K}\right)$ is included in the regression. Specifically, $X_{i t-1}^{K}$ includes the logarithm of firm $i$ 's market capitalization (Size) at the end of month $t$-1, the logarithm of its book-to-market ratio (BTM), its accounting accruals (Accruals), and the three-day abnormal return around firm $i$ 's most recent

\footnotetext{
${ }^{9}$ For example, we define $C A F_{i, t-1}$ as the difference between firm $i$ 's FEPS and I-FEPS, scaled by the standard deviation of the former within each industry. We also try defining the industries using 2-digit SIC codes.

${ }^{10}$ Suppose that Firm X (the firm for which the analyst is forecasting) has an EPS forecast of \$2.00. Firm Y is the only other firm in the industry and its total forecasted earnings are $\$ 2,100$ and it has 1,000 common shares outstanding. Thus, Firm Y's forecasted EPS is $\$ 2.10$. So, the industry median forecasted EPS is $\$ 2.05$. CAF for firm $\mathrm{X}$ is $(\$ 2.00-\$ 2.05) \div|\$ 2.05|=-0.02$. Reconsider the above example but now Firm $\mathrm{Y}$ has 2,000 shares outstanding. Firm Y's forecasted EPS is $\$ 2,100 \div 2,000=\$ 1.05$. The industry median is now $\$ 1.525$ and $C A F$ for firm $\mathrm{X}$ is $(\$ 2.00-\$ 1.525) \div|\$ 1.525|=0.31$. Note that the stability of the anchor (i.e., the industry median forecasted $E P S)$ also significantly affects the anchoring bias. We provide more detailed discussions in section 7.1.
} 
earnings announcement before the beginning of month $t\left(E S_{\text {recent }}\right)$. The lagged information is used for all of the control variables to ensure that the values of these variables have been known by investors at the beginning of month $t$ to avoid any look-ahead bias. We also control for past returns in our specifications. When $F E$ or ECAR is the dependent variable, we simply use the six-month buy-and-hold return in the prior six months (Ret-6:0). However, when $B H A R_{0,1}$ is the dependent variable, we control for a one-month lag of past six-month buy-and-hold return (Ret-7:1) and the past one-month return $\left(\right.$ Ret $\left._{-1: 0}\right)$, because previous research has shown the importance of intermediate-term momentum and short-term reversal (Jegadeesh and Titman (1993, 2001)). In addition, we control for the following three additional variables when $F E$ is the dependent variable: Experience (the natural logarithm of one plus the average number of months current analysts have been following the firm), Breadth (the natural logarithm of the average number of stocks followed by current analysts) and Horizon (the natural logarithm of one plus the number of months before firm i's next earnings announcement). The detailed definitions of these variables are described in Appendix 1.

If $\mathrm{H} 1$ is correct, the coefficient of $C A F$ should be negative, when $F E$ is the dependent variable. In essence, when F-FEPS is low relative to I-FEPS, analysts may anchor on I-FEPS and issue over-optimistic forecasts. This would lead to low subsequent stock returns as market participants gradually revise and correct their optimism. Then, we expect negative earnings surprises when the true earnings are announced. Therefore, if $\mathrm{H} 2$ is correct, we expect that the coefficient of $C A F$ should be positive, when $B H A R_{0,1}$ is the dependent variable. We also expect that the coefficient of $C A F$ should be positive when ECAR is the dependent variable, as investors realize their initial mistake when subsequent earnings are released. If $\mathrm{H} 3$ is correct, the coefficient of $C A F$ should be positive when Split is the dependent variable. In other words, the 
managers would prefer to reduce the FEPS by splitting their stocks to avoid pessimistic earnings forecasts from analysts and undervaluation from investors. We use the Fama-MacBeth (1973) procedure to estimate equation (1), when the dependent variable is continuous (FE, BHAR, or $E C A R)$. The Newey-West (1997) heteroskedasticity and autocorrelation consistent estimates of standard errors are used to compute the $t$-statistics on the estimated coefficients.

\section{B. Portfolio sorts}

Our second approach is based on portfolio sorts. At the end of each calendar month, we first rank all firms in the sample and group them into quintiles (G1 to G5) according to their market capitalization (Size). Within each Size group, we further sort all firms in the group into five subgroups (E1 to E5) based on their $C A F$ measures. We then analyze the behavior of different variables across all 25 portfolios. To test the first hypothesis, we consider $F E$ as the dependent variable.

To test the second hypothesis, we consider Alpha and ECAR. Alpha is the intercept from a time-series regression based on the Fama and French (1993) three-factor model plus a Carhart (1997) momentum factor described as follows:

$$
R_{p, t}-R_{f, t}=\alpha_{p}+\beta_{p}^{M}\left(M k t_{t}-R_{f, t}\right)+\beta_{p}^{S} S M B_{t}+\beta_{p}^{H} H M L_{t}+\beta_{p}^{U} U M D_{t}+\varepsilon_{i, t}
$$

where $R_{p}$ is the monthly return on portfolio $p, M k t$ is the monthly return on the market portfolio, and $R_{f}$ is the monthly risk-free rate. $M k t-R_{f}, S M B$, and $H M L$ are returns on the market, size, and book-to-market factors, respectively, as constructed by Fama and French (1993). UMD is Carhart's (1997) momentum factor. $R_{f}$ is proxied by the one-month U.S. Treasury-bill rate. $H M L$ (High minus Low) is the difference between the return on a portfolio of high (the top 30\%) bookto-market stocks and the return on a portfolio of low (the bottom 30\%) book-to-market stocks. 
$S M B$ (Small minus Big) is the difference between the return on a portfolio of small (the bottom $50 \%$ ) stocks and the return on a portfolio of large (the top 50\%) stocks. UMD is the difference between the return on a portfolio of stocks with high (the top 50\%) prior-year returns and the return on a portfolio of stocks with low (the bottom 50\%) prior-year returns, skipping the return in the formation month. Factor returns and the risk-free rates are from Kenneth French's website. ${ }^{11}$ We estimate the intercept (Alpha) for each of the 25 portfolios.

To test our different hypotheses, we form a hedge portfolio that are long in stocks in the highest $C A F$ group and short in stocks in the lowest $C A F$ group. We then test the statistical significance of $F E$, Alpha or ECAR, in each of the hedge portfolios.

\section{Sample and Descriptive Statistics}

\section{A. Sample selection}

Our basic sample consists of all NYSE, Amex and Nasdaq-listed common stocks in the intersection of (a) the CRSP stock file, (b) the merged Compustat annual industrial file, and (c) the Institutional Brokers' Estimate System (I/B/E/S) unadjusted summary historical file for the period from January 1983 to December $2005 .^{12}$ To be included in the sample for a given month, $t$, a stock must have satisfied the following criteria. First, the mean of analysts' forecasts (i.e., the consensus forecast) of the one-year-ahead ( $F Y 1)$ earnings per share in the previous month, $t$ - 1 , is

\footnotetext{
${ }^{11}$ http://mba.tuck.dartmouth.edu/pages/faculty/ken.french/.

${ }^{12}$ Though I/B/E/S provides data starting from 1976, we restrict our sample period to January 1983 to December 2005 for two reasons. First, before January 1983, the coverage of stocks by I/B/E/S was limited, which would reduce the power of our tests. Second, the I/B/E/S detailed unadjusted historical file begins in 1983 . Hence, we can only conduct robustness checks on the results with the detailed file after 1983. Extending the sample period to 1976 does not materially change our results.
} 
be available from the $\mathrm{I} / \mathrm{B} / \mathrm{E} / \mathrm{S}$ unadjusted summary historical file. Second, its stock returns in the current month, $t$, and the previous six months, $t-6$ to $t-1$, are available from CRSP, and sufficient data are available to obtain market capitalization and stock prices in the previous month, $t-1$. Third, sufficient data from CRSP and Compustat are available to compute the Fama and French (1992, 1993) book-to-market ratio as of December of the previous year. In addition, stocks with share prices lower than five dollars at the end of the previous month, $t-1$, are excluded, as are stocks for which Compustat reports negative book values of stockholders' equity (Item \#60) as of the previous month, $t-1$. This screening process yields 712,563 stock-month observations or an average of 2,699 stocks per month. ${ }^{13}$

It is important to emphasize the use of $\mathrm{I} / \mathrm{B} / \mathrm{E} / \mathrm{S}$ unadjusted data instead of $\mathrm{I} / \mathrm{B} / \mathrm{E} / \mathrm{S}$ adjusted data. A firm's unadjusted FEPS is the actual forecast published in an analyst's report, while an adjusted FEPS has been adjusted for stock splits and stock issuance on the basis of the number of shares outstanding as of the latest data release day. Consequently, trading strategies based on FEPS are valid only when the unadjusted FEPS is used, because this measure reflects the information historically available to investors at that time. The adjusted FEPS contains expost information reflecting stock splits, which could induce severe selection biases. The importance of using unadjusted I/B/E/S data has been recognized by previous studies, such as

\footnotetext{
${ }^{13}$ Following previous studies (for example, Jegadeesh and Titman (2001)), we remove stocks with prices under $\$ 5$ because such stocks not only have few analysts following them, but they also incur large transaction costs due to their poor market liquidity (thin trading and large bid-ask spreads), which could distort the feasibility of any trading strategy. We also remove stocks with negative book value of stockholders' equity simply to make sure that our results are not driven by financially distressed firms. Including these observations leads to (untabulated) results that are economically and statistically more significant.
} 
that of Diether, Malloy, and Scherbina (2002), and it has become the standard treatment in studying analysts' forecasts.

\section{B. Sample characteristics}

Table 1 provides summary descriptive statistics describing our sample. All of the independent variables, as mentioned above, are either lagged by one month or computed based on public information as of the previous month, $t$-1, in order to guarantee that they are already available to investors at the beginning of each month and can be used to execute our trading strategies. Table 1 reports the time-series averages of the cross-sectional means, medians, standard deviations and other statistics. Table 1 shows that all of the variables exhibit substantial variation, suggesting that portfolio sorting strategies based on these firm characteristics should offer reasonable statistical power for our tests. The mean and median of firm size (Size) are $\$ 2.03$ billion and $\$ 0.35$ billion, respectively, which are much larger than the corresponding values for all CRSP stocks (an untabulated result). This reflects the fact that the sample of firms covered by I/B/E/S omits many small stocks. Since the return anomaly reported in this study is stronger for small stocks, the sample selection criteria actually bias against finding significant results.

\section{[Insert Table 1 Here]}

Table 2 reports the univariate correlations among these variables. $C A F$ is significantly and positively correlated with $F-F E P S$, Size, and $E / P_{t-1} . C A F$ is negatively correlated with $F E$ but positively with BHAR and ECAR, although none of them are statistically significant. The correlations among control variables are generally low, suggesting that multicollinearity is not an important concern in the regressions.

[Insert Table 2 Here] 


\section{Empirical Results}

\section{A. Anchoring and forecast errors}

Results from regressions testing $\mathrm{H} 1$ are reported in Panel A of Table 3. Three different models with an increasing number of control variables are considered. The first column reports the results of a model which controls for Size, BTM and $R E T_{-6: 0}$. In the second column, Accruals and $E S_{\text {recent }}$ are added as control variables. In the last column, results including $E / P$ and three other control variables specific to the FE regressions (Experience, Breadth, and Horizon) are reported. Consistent with $\mathrm{H} 1$, the coefficient of $C A F$ is significant and negative in all three models. The effect is also statistically significant, with $t$-statistics ranging from -2.42 to -2.91 . The effect is also economically significant. For example, an increase of $C A F$ by one standard deviation increases $F E$ by approximately $7 \%$ of its mean. ${ }^{14}$

As robustness checks, we consider two alternative dependent variables. In the first alternative specification, we use the consensus forecast of long-term growth rates $(L T G)$ as reported in the $\mathrm{I} / \mathrm{B} / \mathrm{E} / \mathrm{S}$ unadjusted summary file. In the second one, we use the revision of longterm growth rates $(R L T G) . R L T G$ is estimated as the slope coefficient $\left(t_{i}\right)$ in a time-series regression of $L T G_{i, t}=a_{i}+t_{i}$ Time $_{t}+e_{i, t}$ over the next 25 months beginning from the previous month. This measures the monthly adjustment of $L T G .{ }^{15}$ Consistent with the results tabulated in Panel A of Table 3, the coefficient of $C A F$ is significantly negative in the first case (with a $t$ statistic of -11.94) and significantly positive in the second case (with a $t$-statistic of 2.77). In

\footnotetext{
${ }^{14}$ We estimate the effect as the product of 0.016 (from column 3 of Panel A, Table 3) and 2.673 (from Table 1) divided by 0.604 (from Table 1), which equals 0.0708 .

${ }^{15}$ We require in this test that long-term growth rate data be available for at least twelve months.
} 
other words, the results in Table 3 show that analysts anchor on I-FEPS when they forecast earnings and thus are optimistic for firms with a low FEPS. These additional untabulated results show that analysts are subject to a similar anchoring phenomenon when they forecast long-term growth rates of earnings and that they gradually correct their initial forecast errors over time.

\section{[Insert Table 3 Here]}

Panel B of Table 3 provides the results of the portfolio sorts based on size (from G1 to G5) and $C A F$ (from E1 to E5). The last column of the panel reports the results of the partitions based on $C A F$ for firms of all sizes pooled together. As we go from E1 (the portfolio of firms with the lowest $C A F$ ) to E5 (the portfolio of firms with the highest $C A F$ ), the average value of $F E$ decreases monotonically. The difference in the average value of $F E$ between E5 and E1 is statistically significant with a $t$-statistic of -5.28 . The other five columns report the mean values of $F E$ for different portfolios based on size and $C A F$. For all levels of $C A F$, the mean value of $F E$ increases as firm size decreases. The effect is monotonic in virtually all cases (except between G4 and G5 for E4). More importantly for our purpose, $F E$ decreases in all size groups as $C A F$ increases. However, both the magnitude and the statistical significance of the difference between firms with high $C A F$ and low $C A F$ decrease as firm size increases. For example, the magnitude of the difference in $F E$ between high and low $C A F$ firms decreases in absolute value from -0.253 to -0.016 as firms size increases. Similarly, the $t$-statistic of the difference decreases in absolute value from -5.82 to -1.92 as firm size increases from G1 to G5. Results in Appendix 2 indicate that sorting based on size and $L T G$ or $R L T G$ gives similar conclusions. The results from the portfolio sorts are therefore consistent with the predictions of H1.

\section{B. Anchoring and future stock returns}


Panel A of Table 4 presents the results of regressions of a one-month ahead return $\left(B H A R_{0: 1}\right)$ on $C A F$ and our control variables designed to test $\mathrm{H} 2$. For all three models, the coefficient of $C A F$ is significant and positive, with $t$-statistics ranging from 3.43 to 3.59 . The economic effect is such that increasing $C A F$ by one standard deviation increases BHAR by approximately $21 \%$ of its mean value. ${ }^{16}$

\section{[Insert Table 4 Here]}

Panel B of Table 4 provides the results of portfolio sorts based on size (from G1 to G5) and $C A F$ (from E1 to E5). For each portfolio, we estimate a time-series regression based on the Fama-French and Carhart four-factor model for each portfolio. The intercepts (Alphas) of the test portfolios are reported in Panel B of Table 4. The last column of the panel reports the results of the partitions based on $C A F$ for firms of all sizes pooled together. As we go from E1 (the portfolio of firms with low $C A F$ ) to E5 (the portfolio of firms with high $C A F$ ), the values of Alpha increase monotonically. The difference in Alpha between E5 and E1 (i.e., the hedge portfolio) is $0.76 \%$ per month, or $9.12 \%$ per year, and is statistically significant with a $t$-statistic equal to 4.75. The other five columns report the intercepts for different hedge portfolios based on size and $C A F$. The average values of the abnormal returns (Alpha) are significant and positive for all levels of firm size. However, both the magnitude and the statistical significance decrease as firm size increases. For example, the magnitude of the difference in Alpha between high and low $C A F$ groups decreases from $1.42 \%$ to $0.35 \%$ per month. Similarly, the $t$-statistic of the difference decreases from 7.12 to 2.37 .

\footnotetext{
${ }^{16}$ We estimate the effect as the product of 0.093 (from column 3 of Table 4) and 2.673 (from Table 1) scaled by 1.190 (from Table 1), which equals 0.209
} 
Results in Appendix 3 indicate that using either value-weighed or equal-weighted portfolio raw returns instead of the intercepts (Alpha) from the time-series regressions gives similar results. The results in Table 4 are based on dependent sorts of firms based on Size and $C A F$. These dependent sorts ensure that the number of firms is the same in all portfolios. Untabulated tests indicate that similar, if not stronger, results emerge based on independent sorts, which allow for the number of observations to vary across portfolios. ${ }^{17,18}$ Following the method of Zhang (2006), we also replace Size with alternative proxies that may be correlated with information uncertainty, such as firm age, share price, analyst coverage, and institutional holdings. The results (not tabulated) are similar to those reported in Table 4.

Table 4 focuses on the one-month-ahead return. However, the effect of $C A F$ on future stock returns is not limited to a one-month horizon. Figure 1 plots the average cumulative raw returns at monthly intervals of the hedging strategy of buying the highest $C A F$ decile portfolio and selling the lowest $C A F$ decile portfolio. It appears that the returns on the hedge portfolio using this $C A F$ strategy grow consistently, at least in the first twelve months after portfolio

\footnotetext{
${ }^{17}$ The results remain robust if three-way sorts based on Size, Momentum and CAF; Size, Book-to-market and CAF; Size, earnings surprises (ES) and CAF; Size, forecast E/P ratio and CAF; Size, Accruals and CAF; Size, V/P and $C A F$; or Size, FE scaled by price and $C A F$ are used. Here $V / P$ is the fundamental value-to-price ratio and the fundamental value is estimated using the method proposed by Frankel and Lee (1998). These analyses are not tabulated but available upon request.

${ }^{18}$ One may be concerned that our results are driven by the stock split effect as firms with a high $C A F$ are more likely to split their stocks. Prior studies (Grinblatt et al., (1984)) have documented a positive and significant 3\% abnormal return around stock split announcements. Ikenberry and Ramnath (2002) and Desai and Jain (1997) report an abnormal return of about $7-9 \%$ in the twelve months following a stock split. To ensure that this potential post stock split drift does not cause our findings, we remove firms with a stock split in month $t$ from the regressions. The results remain quantitatively and qualitatively similar.
} 
formation. To formally investigate the $C A F$ effect beyond the one-month horizon, we re-estimate a model similar to the one reported in the last column of Panel A of Table 4 but using returns cumulated over 3, 6, and 12 months after portfolio formation. The coefficients of $C A F$ are 0.121 , 0.227 , and 0.484 with $t$-statistics of $1.96,2.13$, and 2.21 , respectively, suggesting a persistent impact of $C A F$ on long-run returns. Although the cumulative returns grow at a decreasing rate, they do not show any reversal over the next 36 months. This distinguishes the $C A F$ effect from the momentum effect, for which Jegadeesh and Titman (2001) find a dramatic reversal of returns to the momentum strategy after one year.

\section{[Insert Figure 1 Here]}

To put these returns into practical perspective, we consider the effect of transaction costs using the model proposed by Keim and Madhavan (1997) (also used by Barber et al. (2001) and Bushee and Raedy (2006)). Specifically, we estimate the price impact (PriceImpact (\%)) for buyer-initiated trades as follows:

$$
\begin{aligned}
\text { PriceImpact }(\%)= & 1.259+0.336 \times N A S D A Q+0.092 \times T R S I Z E \\
& -0.084 \times M K T C A P+13.807 \times \text { InvPrice } .
\end{aligned}
$$

For seller-initiated trades, we estimate the price impact as:

$$
\begin{aligned}
\text { PriceImpact }(\%)= & 1.223+0.058 \times N A S D A Q+0.214 \times T R S I Z E \\
& -0.059 \times M K T C A P+6.537 \times \text { InvPrice } .
\end{aligned}
$$

Here $N A S D A Q$ is an indicator variable that equals one if the stock being traded is listed on Nasdaq and 0 otherwise. TRSIZE is the ratio of the order value to the stock's market capitalization. MKTCAP is the logarithm of the stock's market capitalization at $t+1$. InvPrice is one over the price per share of the stock being traded at $t+1$. The constant terms in both models represent explicit transaction costs. To obtain conservative estimates, we use the $99^{\text {th }}$ percentile of the distribution of trade dollar size for the month under consideration (from the ISSM and 
TAQ databases). In addition, we assume the cost of shorting low $C A F$ stocks is twice as much as that of shorting high $C A F$ stocks.

Untabulated results indicate that the mean of the 12-month cumulative raw returns associated with the $C A F$ hedge portfolio is $9.3 \%$ for the whole sample, while the mean of the corresponding estimated trading costs for this portfolio is $3.7 \%$. When we consider different size quintiles, the cumulative hedge portfolio returns vary from $12.9 \%$ for the smallest stocks to $4.4 \%$ for the largest ones, while the estimated transaction costs vary from $6.3 \%$ to $1.2 \%$, respectively. For firms in the middle quintile, the estimates are $12.6 \%$ and $3.8 \%$, respectively. These results suggest that our $C A F$ trading strategies are still profitable even after taking into account transaction costs.

\section{Anchoring and market reactions around earnings announcements}

Having found that future returns and $C A F$ are positively related, we focus next on returns around earnings announcements. Panel A of Table 5 presents the results of regressions of the earnings announcement return $(E C A R)$ against $C A F$ and other control variables. ECAR is the three-day accumulative abnormal return relative to the CRSP value-weighted index surrounding the subsequent earnings announcement date after portfolio formation. For all three models, the coefficient of $C A F$ is significantly positive with $t$-statistics ranging from 4.20 to 4.77 . The economic effect is such that increasing $C A F$ by one standard deviation increases ECAR by approximately $113 \%$ of its mean value. ${ }^{19}$

\section{[Insert Table 5 Here]}

\footnotetext{
${ }^{19}$ We estimate the effect as the product of 0.050 (from column 3 of Panel A, Table 5) and 2.673 (from Table 1) scaled by 0.118 (from Table 1), which equals to $113.26 \%$.
} 
Panel B of Table 5 provides the results of the earnings announcement returns (ECAR) for portfolios sorted based on size (from G1 to G5) and CAF (from E1 to E5). For each portfolio, we estimate the average of the three-day cumulative abnormal returns surrounding the subsequent earnings announcement dates after portfolio formation. The last column of the panel reports the results of the partitions based on $C A F$ for firms of all sizes pooled together. As we go from E1 (the portfolio of firms with the lowest $C A F$ ) to E5 (the portfolio of firms with the highest $C A F$ ), the average value of earnings surprises increases. The average return of the hedge portfolio (long E5 and short E1) is $0.37 \%$ over the three-day period around the subsequent earnings announcement and is statistically significant with a $t$-statistic equal to 6.71 .

In addition, the returns of the hedge portfolios are positive for all size groups. However, both the magnitude and the statistical significance decrease as firm size increases. For example, the magnitude of the difference in three-day earnings surprises decreases from $0.51 \%$ to $0.12 \%$ from G1 to G5. Similarly, the $t$-statistic for the difference also decreases from 5.07 to 1.16 as firm size increases. Overall, the returns of the hedge portfolios surrounding earnings announcements are significant for the three smallest size quintiles and in the pooled sample. The results in Table 5 indicate that a substantially part of the $C A F$ effect is concentrated surrounding the earnings announcement dates. Based on a one-year holding horizon, on average, such returns account for approximately $16 \%$ of the $C A F$ effect, even though they accounts for less than $5 \%$ of the trading dates ${ }^{20}$. The results also suggest that the $C A F$ effect cannot be reconciled by any

\footnotetext{
${ }^{20}$ The average three-day announcement return for the hedge portfolio is $0.37 \%$ per quarter and the average annualized hedge portfolio return is $9.3 \%$. Thus, the hedge portfolio return surrounding the earnings announcement period accounts for $(0.37 \% \times 4) \div 9.3 \%=15.91 \%$ of the overall portfolio return, even though the trading days around earnings announcements account for only $(3 \times 4) \div 250=4.8 \%$ of the total number of trading days in the year.
} 
obvious risk-based explanation. If the significant excess returns from the $C A F$ strategy are generated because of benchmarking errors from any asset-pricing model, they would be expected to accrue relatively smoothly over the year, not clustered around earnings announcements. ${ }^{21}$

\section{Anchoring and stock splits}

Before testing $\mathrm{H} 3$, we examine the time-series behavior of forecast earnings per share and aggregate earnings. Figure 2 indicates a stable pattern in the cross-sectional distribution of the forecasts of nominal EPS. Untabulated results indicate that such a pattern also exists in realized nominal EPS. The cross-sectional median of FEPS rarely deviates from a small range bounded by $\$ 1.5$ and $\$ 2$ in our sample period covering 1983 to $2005 .^{22}$ In contrast, the median of total earnings forecasts (TFE) in the cross-section almost triples from US\$14 million to US\$37 million during the same time period.

\section{[Insert Figure 2 Here]}

The results in Figure 2 provide an indirect test of $\mathrm{H} 3$. These differences in the time-series are consistent with the idea that firms manage their nominal earnings per share to around an optimal level. Panel A of Table 6 presents the results of logit regressions of Split against CAF and the control variables. In all three models, the coefficient of $C A F$ is significant and positive, with $t$-statistics ranging from 2.59 to 2.86 . The economic effect is such that increasing $C A F$ by

\footnotetext{
${ }^{21}$ This methodology, which has been initially proposed by Chopra, Lakonishok, and Ritter (1992) to study overreaction, has been applied in several studies to test for the possibility that investors have biased expectations. La Porta, Lakonishok, Shleifer, and Vishny (1997) study stock price reactions around earnings announcements to examine whether the superior return to value stocks is resulted from investors' expectations biases.

${ }^{22}$ Benartzi, Michaely, Thaler, and Weld (2007) also find that the cross-sectional distribution of nominal share prices is very stable over time.
} 
one standard deviation increases the odds of a stock split by approximately $5 \%$. We also find that large and growth firms are more likely to engage in a stock split as documented by a positive and significant coefficient on $\operatorname{Ln}($ Size $)$ and a negative and significant coefficient on $\operatorname{Ln}(B T M)$, where $B T M$ (book-to-market ratio) is an inverse measure of growth opportunities.

\section{[Insert Table 6 Here]}

Panel B of Table 6 reports the average stock split ratio $(S S R)$ of the portfolio sorts based on Size (from G1 to G5) and CAF (from E1 to E5). The last column of the panel reports the results of the partitions based on $C A F$ for firms of all sizes pooled together. As we go from E1 (the portfolio of firms with the lowest $C A F$ ) to E5 (the portfolio of firms with the highest $C A F$ ), the average value of $S S R$ increases monotonically. The difference in the average value of $S S R$ between E5 and E1 is statistically significant with a $t$-statistic equal to 8.48 in the pooled sample. The results also indicate that for a given $C A F$ group, the stock split ratio increases monotonically with firm size. More importantly, the difference in SSR between E1 and E5 is significant in all size groups. In addition, the magnitude of the difference increases as firm size increases. For example, the magnitude of the difference increases from 0.098 to 0.166 as firm size increases from G1 to G5. Using the number of stock splits instead of SSR gives similar results (untabulated). All of these results are consistent with those reported in Panel A of Table 6.

\section{E. Consequences of stock splits}

Our key measure focuses on earnings per share. Naturally, this variable will be affected by the number of shares outstanding and consequently, by stock splits. We next examine consequences of stock splits on analyst forecast revisions (Panel A of Table 7), analyst forecast errors (Panel B of Table 7), and earnings surprises (Panel $\mathrm{C}$ of Table 7). To do so, we use a 
"difference-in-differences" approach. We first identify firms which carry out significant stock splits (one share is split into 1.5 or more shares) in each month. In Panels A and B, we match those firms with firms that have no stock split but are similar in firm size, book-to-market ratios, forecast errors, and $C A F$. The values of these matching variables for the month prior to the stock split are used to match firms. We then compute the changes in the differences in forecast revisions (Panel A) and the differences in forecast errors (Panel B) between the two groups of firms. Panel C presents, for each firm and each month, the change in ex-post and ex-ante earnings surprises $(E S)$. Firms with a stock split are again matched with firms without a split by size, book-to-market ratio, and $C A F$. The difference in changes in earnings surprises between the two groups is reported. We next repeat the procedure of double sorts based on Size and CAF.

\section{[Insert Table 7 Here]}

Panel A of Table 7 shows that there is an increase in earnings forecast revisions for firms after a stock split compared to firms which do not split. In 28 of the 30 Size-CAF sorted portfolios, the differences in forecast revisions between split firms and no-split firms are positive. The result suggests that analysts in general revise their earnings forecasts more upward for split firms than for no-split firms. The last column which pools all the sizes together indicates that the effect is more significant for firms with a low $C A F$ than for firms with a high $C A F$. For example, the differences decrease monotonically from 0.075 to 0.011 as the $C A F$ increases from E1 to E5. This suggests that the effect of a stock split on earnings revisions concentrates on firms with a low ex-ante $C A F$. In addition, the differences in forecast revisions between split firms and matched no-split firms are statistically significant in all five size groups, and the difference for the entire sample is 0.029 with a $t$-statistic of 16.78 . 
Panel B shows that when the ex-ante CAF level is low, there is an increase in the forecast errors for firms after a stock split compared with firms which do not split their stocks. However, this effect is weaker as the $C A F$ increases, and is even negative for portfolios in which $C A F$ is the highest (E5). The differences in forecast errors between split firms and matched no-split firms are statistically significant in four of the five size groups and the difference for the entire sample is 0.017 , with a $t$-statistic of 5.53 .

Panel $\mathrm{C}$ shows that there is often a decrease in earnings surprises after a stock split compared with firms which do not split their stocks. In 29 of the 30 Size-CAF sorted portfolios, the differences in changes of earnings surprises between split firms and no-split firms are negative and highly significant. More importantly, the magnitude is larger for firms with a low $C A F$ than for firms with a high $C A F$, especially in the three smallest size groups.

\section{Robustness Checks}

\section{A. Cross-sectional partitions}

Taken together, these results are consistent with our hypotheses, and they suggest that analysts and investors anchor on the industry median FEPS. It seems reasonable that any anchoring effect should be stronger when the anchor is more stable. To test this conjecture, we re-estimate the models from Panel A in Tables 3 to 5 by splitting the entire sample into two subgroups based on the stability of the anchor. We use the full specification reported in the last column of each table. The stability of the anchor is measured in terms of the coefficient of variation $(C V)$ of $I-F E P S$ corresponding to a period covering the previous 24 months. A lower $C V$ indicates a more stable anchor. The results are reported in Table 8. Control variables are included but are not tabulated. In all of the subsamples, the coefficient on $C A F$ has the predicted 
sign and is significant at the $5 \%$ level or better, except when $F E$ is the dependent variable and the anchor is unstable, in which case the significance is at the $10 \%$ level. Importantly, the coefficient on $C A F$ is economically and statistically more significant in the sub-samples with more stable anchors. In fact, the difference in coefficients between the stable and unstable samples is significant at the $5 \%$ level or better in all cases.

\section{[Insert Table 8 Here]}

We examine the effect of sophistication on anchoring bias. To do so, we split the entire sample into two subgroups based on the sophistication of the market participants. For analysts, the size of the employers is used as a proxy. Prior work (such as Hong and Kubik (2003)) has suggested that analysts working for large brokers produce more informative forecasts. For investors, sophistication is proxied by the percentage of institutional ownership. Prior research has confirmed that institutional investors are more sophisticated than retail investors (Bartov, Radhakrishnan, and Krinsky (2000), and Bhusan (1994)). The results reported in Table 8 indicate that the effect of anchoring is weaker when market participants are sophisticated than when they are not. The effect is economically and statistically more significant in the sub-samples dominated by unsophisticated participants. The difference between the coefficients on $C A F$ across the subsamples is significant at the $5 \%$ level or better for the classification based on institutional investors. The difference is significant at the $10 \%$ level for the classification based on analysts.

\section{B. Alternative anchors}

As we discussed in Section II, anchoring is a well-established principle in the psychology literature and we believe that anchoring bias is relevant for the understanding of the financial 
markets. However, what is less clear is precisely what anchors should be relevant. In this study, we examine if forecasted I-EPS is a significant one. As explained in Section III, our discussions with analysts led us to believe that the industry median forecasted EPS is a plausible anchor and our empirical tests are very consistent with this view. However, we do not argue that this is the only possible anchor in the financial markets but rather that it is an important one. Naturally, all variables that are closely related to industry median forecasted EPS such as the mean, the mode, or even median realized earnings should obtain empirical results that are very similar to those documented in this study. In untabulated tests, we find that it is indeed the case.

We also investigate in greater details the effect of two alternative candidates. First, we construct a measure of cross-sectional anchoring based on the stock price per share. Specifically, we define $C A P$, the analog of $C A F$, as the difference between the stock price per share of a firm and the industry median stock price per share, scaled by the absolute value of the latter. Second, we consider the role of time-series anchoring by constructing $T A F$, a measure of time-series anchoring on EPS. We define TAF as the difference between firm $i$ 's FEPS and its most recently announced EPS, scaled by the absolute value of the latter.

We add $C A P$ and $T A F$ as independent variables in our baseline regressions (similar to those reported in Table 3-Table 5). Untabulated results indicate that the inclusion of alternative anchoring measures does not significantly weaken the explanatory power of $C A F$ in any of these regressions. We also consider a "transposed Fama-MacBeth" approach. That is, we divide our overall sample in 20 categories based on price ranges and we run 20 cross-sectional regressions (one per price range). We then calculate the means and the standard errors of the estimated coefficients on $C A F$. Untabulated results indicate that the ratios of the mean to the standard errors are equal to $4.82,2.54$, and 1.93 when the dependent variables are $F E, B H A R_{0: 1}$, and 
$E C A R$, respectively. This shows that even after controlling for price levels, our regression results still hold.

Finally, in Table 9, we consider a portfolio trading strategy similar to that used in the Panel B of Table 4, but we focus on $C A P$ and $T A F$ (instead of $C A F$ ). Panel A presents the results for the partitions based on $C A P$. In sharp contrast to the strong return predictability of $C A F$, our results suggest that the $C A P$ measure cannot predict future one-month returns at all. The fourfactor adjusted alphas are not monotonically increasing or decreasing as CAP increases within each size group. Further, the hedging portfolios (i.e., E5-E1) based on the CAP measure in all size groups exhibit no significant abnormal returns (i.e., alphas). Untabulated tests indicate that partitions based on dividend per share and book value of equity per share yield a similar lack of predictive power. In other words, our results do not generalize to any "per share" variables.

\section{[Insert Table 9 Here]}

Panel B presents the results for the partitions based on $T A F$. Results indicate that $C A F$ has a much stronger return predictability than $T A F$. The average one-month hedging portfolio return (i.e., long the highest $T A F$ quintile and short the lowest $T A F$ quintile simultaneously) based on $T A F(0.21 \%)$ is less than one third of that based on $C A F(0.76 \%)$. More importantly, $C A F$ is able to generate significant hedging portfolio returns in all size groups, while $T A F$ only has return predictability in the two smallest size quintiles. In addition, $C A F$ has a reasonably symmetric effect between the long and short portfolios, while the effect of $T A F$, if any, is concentrated in the short portfolios. 


\section{Conclusion}

The effect of anchoring bias on market participants such as sell-side analysts and investors has not been extensively investigated previously. This study tests the proposition that market participants are affected by anchoring bias when they estimate the future profitability of a firm, and the empirical results are consistent with this hypothesis. We find that analysts' earnings forecasts for firms with low forecast EPS relative to their corresponding industry median do indeed be more optimistic than forecasts for similar firms with high EPS. This is consistent with the hypothesis that analysts anchor their forecasts using the industry median. In addition, future stock returns are significantly higher for firms with EPS forecasts that are high relative to the industry median than for similar firms whose EPS forecasts are relatively low. The positive relationship between FEPS and future stock returns cannot be explained by risk factors, the book-to-market ratio, the earnings-to-price ratio, price or earnings momentum, accounting accruals or nominal share price. In addition, earnings surprises are more positive for firms with high EPS forecasts relative to the industry median. All these results are stronger when the industry median is more stable and when market participants are less sophisticated. Finally, the likelihood of a stock split within a year increases when a firm's EPS forecast is high relative to the industry median. Stock-split firms experience larger positive earnings forecast revisions, larger positive forecast errors, and greater increases in earnings surprises than firms which have not spit their stocks, especially for firms with a low EPS forecast relative to the industry median. 


\section{References}

Abarbanell, J. S. "Do Analysts' Earnings Forecasts Incorporate Information in Prior Stock Price Changes?" Journal of Accounting and Economics, 14 (1991), 147-165.

Angel, J. J. “Tick Size, Share Prices and Stock Splits.” Journal of Finance, 52 (1996), 655-681.

Baker, M.; R. Greenwood; and J. Wurgler. "Catering Through Nominal Share Prices." Journal of Finance, 64 (2009), 2559-2589.

Baker, M.; X. Pan; and J. Wurgler. "A Reference Point Theory of Mergers and Acquisition." Working paper, Harvard University (2009)

Barber, B.; R. Lehavy; M. McNichols; and B. Trueman. "Can Investors Profit from the Prophets? Consensus Analyst Recommendations and Stock Returns." Journal of Finance, 56 (2001), 531-563.

Bartov, E.; S. Radhakrishnan; and I. Krinsky. "Investor Sophistication and Patterns in Stock Returns After Earnings Announcements.” The Accounting Review, 75 (2000), 43-63.

Benartzi, S.; R. Michaely; R. H. Thaler; and W. C. Weld. "The Nominal Price Puzzle.” Working paper, UCLA (2007)

Bhushan, R. "An Informational Efficiency Perspective on the Post-earnings-announcement drift." Journal of Accounting and Economics, 18 (1994), 45-65.

Block, R. A. and D. Harper, "Overconfidence in Estimation: Testing the Anchoring-andAdjustment Hypothesis." Organizational Behavior and Human Decision Processes, 49 (1991), 188-207.

Brewer, N. T.; G. B. Chapman; J. A. Schwartz; and G. R. Bergius. "The Influence of Irrelevant Anchors on the Judgments and Choices of Doctors and Patients." Medical Decision Making, 27 (2007), 203-211.

Bushee, B. and J. S. Raedy. "Factors Affecting the Implementability of Stock Market Trading Strategies.” Working paper, Wharton School, University of Pennsylvania (2006)

Cameron, A. C.; J. B. Gelbach; and D. L. Miller. "Robust Inference with Multi-way Clustering." Journal of Business and Economic Statistics (forthcoming, 2010)

Campbell, S. D. and S. A. Sharpe. "Anchoring Bias in Consensus Forecasts and its Effect on Market Prices.” Journal of Financial and Quantitative Analysis 44 (2009), 369-390.

Carhart, M. M. "On Persistence in Mutual Fund Performance." Journal of Finance, 52 (1997), 57-82. 
Chapman, G. B. and B. H. Bornstein. "The More You Ask For, the More You Get: Anchoring in Personal Injury Verdicts.” Applied Cognitive Psychology, 10 (1996), 519-540.

Chapman G. B. and E. J. Johnson. "Incorporating the Irrelevant: Anchors in Judgments of Belief and Value." In: T. Gilovich, D.W. Griffin and D. Kahneman, Editors, The Psychology of Judgment: Heuristics and Biases, Cambridge University Press, New York (2002).

Chopra, N.; J. Lakonishok; and J. R. Ritter. "Measuring Abnormal Performance: Do Stocks Overreact?" Journal of Financial Economics, 31 (1992), 235-268.

Clement, M. B. and S. Y. Tse. "Financial Analyst Characteristics and Herding Behavior in Forecasting." Journal of Finance, 60 (2005), 307-341.

Daniel, K.; D. Hirshleifer and A. Subrahmanyam. "Investor Psychology and Security Market Under- and Overreactions." Journal of Finance, 53 (1998), 1839 - 1885.

Davis, H. L.; S. J. Hoch; and E. K. Ragsdale. "An Anchoring and Adjustment Model of Spousal Predictions.” Journal of Consumer Research, 13 (1986), 25-37.

De Bondt, W. F. and R. H. Thaler. "Do Security Analysts Overreact?" American Economic Review, 80 (1990), 52-57.

De George, F.; J. Patel; and R. Zeckhauser. "Earnings Management to Exceed Thresholds." Journal of Business, 72 (1999), 1-33.

Desai, H. and P. Jain. "Long-run Common Stock Returns Following Stock Splits and Reverse Splits.” Journal of Business, 70 (1997), 409-433.

Diether, K. B.; C. J. Malloy; and A. Scherbina. "Difference of Opinion and the Cross Section of Stock Returns.” Journal of Finance 57 (2002), 2113-2141.

Easterwood, J. C. and S. R. Nutt. "Inefficiency in Analysts' Earnings Forecasts: Systematic Misreaction or Systematic Optimism?” Journal of Finance, 54 (1999), 1777-1797.

Englich, B. and T. Mussweiler. "Sentencing under Uncertainty: Anchoring Effects in the Court Room." Journal of Applied Social Psychology 31 (2001), 1535-1551.

Fama, E. F. "Market Efficiency, Long-term Returns, and Behavioral Finance." Journal of Financial Economics, 49 (1998), 283-306.

Fama, E. F. and K. R. French. "The Cross-section of Expected Stock Returns" Journal of Finance 47 (1992), 427-465.

Fama, E. F. and K. R. French. "Common Risk Factors in the Returns on Stocks and Bonds." Journal of Financial Economics 33 (1993), 3-56. 
Fama, E. F. and K. R. French. "Industry Costs of Equity." Journal of Financial Economics, 43 (1997), 153-193.

Fama, E. F. and J. D. MacBeth. "Risk, Return and Equilibrium: Empirical Tests." Journal of Political Economy, 81 (1973), 607-636.

Frankel, R. and C.M.C. Lee. "Accounting Valuation, Market Expectation, and Cross-sectional Stock Returns." Journal of Accounting and Economics, 25 (1998), 283-319.

George, J. T. and C. Hwang. "The 52-week High and Momentum Investing." Journal of Finance 59 (2004), 2145-2176.

Ginsburgh, V. and J. Ours. "Expert Opinion and Compensation: Evidence from a Musical Competition.” American Economic Review 93 (2003), 289-296.

Grinblatt, M.; R. Masulis; and S. Titman. "The Valuation Effects of Stock Splits and Stock Dividends." Journal of Financial Economics 13 (1984), 461-490.

Hirshleifer, D. "Investment Psychology and Asset Pricing." Journal of Finance, 56 (2001), 1533-1597.

Hogarth, R. Judgment and Choice, John Wiley and Sons, New York (1980).

Hong, H. and J. D. Kubik. "Analyzing the Analysts: Career Concerns and Biased Earnings Forecasts.” Journal of Finance, 63 (2003), 313-351.

Hong, H.; T. Lim; and J. C. Stein. "Bad News Travels Slowly: Size, Analyst Coverage, and the Profitability of the Momentum Strategy." Journal of Finance, 55 (2000), 265-295.

Ikenberry, D. L. and S. Ramnash. "Underreaction to Self-selected News Events: The Cases of Stock Splits." Review of Financial Studies, 15 (2002), 489-526.

Jegadeesh, N. and S. Titman. "Returns to Buying Winners and Selling Losers: Implications for Stock Market Efficiency." Journal of Finance, 48 (1993), 65-92.

Jegadeesh, N. and S. Titman. "Profitability of Momentum Strategies: An Evaluation of Alternative Explanations." Journal of Finance, 56 (2001), 699-720.

Johnson, E. J. and D. A. Schkade. "Bias in Utility Assessments: Further Evidence and Explanations." Management Science 35 (1989), 406-424.

Kahneman, D. and A. Tversky. "Judgment under Uncertainty: Heuristics and Biases", Science 185 (1974), 1124-1131.

Keim, D. B. and A. Madhavan. "Transaction Costs and Investment Style: An Inter-exchange Analysis of Institutional Equity Trades." Journal of Financial Economics, 46 (1997), 265- 
292.

La Porta, R. "Expectations and the Cross Section of Stock Returns." Journal of Finance 51 (1996), 1715-1742.

La Porta, R.; J. Lakonishok; A. Shleifer; and R. W. Vishny. "Good News for Value Stocks: Further Evidence on Market Efficiency.” Journal of Finance, 52 (1997), 859-874.

Latham, G. P.; M. Budworth; B. Yanar; and G. Whyte. "The Influence of a Manager's Own Performance Appraisal on the Evaluation of Others." International Journal of Selection and Assessment 16 (2008), 220-228.

Lichtenstein, S. and P. Slovic. "Reversals of Preference between Bids and Choices in Gambling Decisions." Journal of Experimental Psychology, 89 (1971), 46-55.

Lichtenstein, S.; P. Slovic; B. Fischhoff; M. Layman; and B. Combs. "Judged Frequency of Lethal Events." Journal of Experimental Psychology: Human Learning and Memory 4 (1978), 551-578.

Lopes, L. L. "Averaging Rules and Adjustment Processes: The Role of Averaging in Inference." Report No. 13, Wisconsin Human Information Processing Program, University of Wisconsin (1981)

Lovie, P. "A Note on an Unexpected Anchoring Bias in Intuitive Statistical Inference" Cognition, 21 (1985), 69-72.

Mitchell, M, L. and E. Stafford. "Managerial Decisions and Long-term Stock Price Performance." Journal of Business, 73 (2000), 287-329.

Newey, W. and K. West. "A Simple, Positive Semi-definite, Heteroscedasticity and Autocorrelation consistent covariance matrix." Econometrica 55 (1987), 703-708.

Northcraft, G. B. and M. A. Neale. "Experts, Amateurs and Real Estate: An Anchoring-andadjustment Perspective on Property Pricing Decisions" Organizational Behavior and Human Decision Processes 39 (1987), 84-97.

Peterson, M. A. "Estimating Standard Errors in Finance Panel Data Sets: Comparing Approaches." Review of Financial Studies, 22 (2009), 435-480.

Plous, S. "Thinking the Unthinkable: The Effects of Anchoring on Likelihood Estimates of Nuclear War." Journal of Applied Social Psychology, 19 (1989), 67-91.

Qu, C.; L. Zhou; and Y. Luo. "Electrophysiological Correlates of Adjustment Process in Anchoring Effects.” Neuroscience Letters 445 (2008), 199-203.

Ritov, I. "Anchoring in a Simulated Competitive Market Negotiation." Organizational Behavior and Human Decision Processes, 67 (1996), 16-25. 
Russo, J. E. and P. J. Shoemaker. Decision Traps: Ten Barriers to Brilliant Decision Making and How to Overcome Them. Simon \& Schuster, New York (1989).

Sloan, R. G. "Do Stock Prices Fully Reflect Information in Cash Flows and Accruals about Future Earnings?" The Accounting Review, 71 (1996), 289-315.

Welch, I. "Herding among Security Analysts.” Journal of Financial Economics, 58 (2000), 369396.

Whyte, G. and J. K., Sebenius. "The Effect of Multiple Anchors on Anchoring in Individual and Group Judgment." Organizational Behavior and Human Decision Processes 69 (1997), 75 85.

Wilson, T. D.; C. E. Houston; K. M. Etling; and N. Brekke. "A New Look at Anchoring Effects: Basic Anchoring and its Antecedents." Journal of Experimental Psychology: General, 125 (1996), 387-402.

Wright, W. F. and U. Anderson. "Effects of Situation Familiarity and Financial Incentives on Use of the Anchoring and Adjustment Heuristic for Probability Assessment." Organizational Behavior and Human Decision Processes, 44 (1989), 68-82.

Zhang, X. F. "Information Uncertainty and Stock Returns." Journal of Finance, 61 (2006), 105136.

Zuckerman, M.; R. Koestner; M. J. Colella; and A. O. Alton. "Anchoring in the Detection of Deception and Leakage", Journal of Personality and Social Psychology, 47 (1984), 301-311. 
APPENDIX 1

Definitions of Major Dependent and Independent Variables

\begin{tabular}{ll}
\hline Variable & Definition and data source \\
\hline$C A F:$ & The industry cross-sectional anchoring measure of forecast earnings per share $(F E P S) ; C A F=(F-$ \\
& FEPS - I-FEPS)/II-FEPSI, where F-FEPS presents an individual firm's FEPS and I-FEPS \\
& represents the industry median FEPS. The 48 industries are defined as in Fama and French $(1997)$ \\
& and the definition of 48 industries is available from Ken French's website. \\
& Data source: I/B/E/S and Fama and French (1997).
\end{tabular}

F-FEPS: $\quad$ Mean of an individual firm's forecast one-year-ahead earnings per share in the previous month from the I/B/E/S unadjusted summary historical file. It is also called the consensus EPS forecast. Data source: $\mathrm{I} / \mathrm{B} / \mathrm{E} / \mathrm{S}$.

TFE: $\quad$ Total forecast earnings $=$ F-FEPS $\times$ Number of shares outstanding.

Data source: CRSP and I/B/E/S.

Size: $\quad$ The market value of a firm's equity at the end of the previous month, as retrieved from CRSP.

Data source: CRSP.

BTM: $\quad$ The Fama and French (1993) book-to-market ratio, where the value for July of year $y$ to June of year $y+1$ is computed using the book value of equity for the fiscal-year-end in calendar year $y-1$ from Compustat and the market value of equity at the end of December of year $y-1$ from CRSP.

Data source: CRSP and Compustat.

FE: $\quad$ Forecast error; $F E=(F-F E P S-$ Actual EPS $) /$ Actual EPSI, where F-FEPS represents a firm's FEPS and Actual EPS is its actual EPS that will be announced at the end of the fiscal year.

Data source: I/B/E/S.

ECAR: $\quad$ The three-day (day -1 to date +1 ) cumulative abnormal return relative to the CRSP value-weighted index surrounding the next earnings announcement date after portfolio formation over the next twelve months.

Data source: CRSP and I/B/E/S.

Split: $\quad$ A dummy variable that equals 1 if this firm carries out a significant stock split (i.e., one share is split into 1.5 or more shares) in the month, and 0 otherwise.

Data source: CRSP.

$B H A R_{0: 1}: \quad$ One-month buy-and-hold return after portfolio formation.

Data source: CRSP.

Ret $_{-6: 0}$ : $\quad$ Buy-and-hold return over the past six months as of the previous month.

Data source: CRSP.

Ret $_{-1: 0}: \quad \quad$ The past one-month return.

Data source: CRSP.

Ret $_{-7:-1}$ : $\quad$ A one-month lag of the past six-month buy-and-hold return.

Data source: CRSP. 
Accruals: $\quad$ Total accruals scaled by average total assets $=((\Delta \mathrm{CA}-\Delta \mathrm{Cash})-(\Delta \mathrm{CL}-\Delta \mathrm{STD}-\Delta \mathrm{TP})-\mathrm{Dep}) / \mathrm{TA}$, as defined in Sloan (1996), where $\Delta \mathrm{CA}=$ change in current assets (Compustat Item \#4), $\Delta \mathrm{Cash}=$ change in cash and cash equivalents (Compustat Item \#1), $\Delta \mathrm{CL}=$ change in current liabilities (Compustat Item \#5), $\triangle \mathrm{STD}=$ change in debt included in current liabilities (Compustat Item \#34), $\Delta \mathrm{TP}=$ change in income taxes payable (Compustat Item \#71), Dep = depreciation and amortization expense (Compustat Item \#14) and TA is the average of the beginning and end of year book value of total assets (Compustat Item \#6).

Data source: Compustat.

$E / P_{t-1}: \quad$ The historical earnings-to-price ratios. $E / P_{t-1}$ is calculated as follows: First, net income before extraordinary items (Compustat Item \#237) for the most recently announced fiscal-year-end (I/B/E/S Item FYOEDATS) is divided by the number of shares outstanding to obtain the historical earnings per share $(E)$ for month $t-1 . E$ is then divided by the stock price $(P)$ on the same day to obtain $E / P_{t-1}$.

Data source: Compustat, CRSP and I/B/E/S.

$E S_{\text {recent }}: \quad$ The three-day (day -1 to day +1 ) cumulative abnormal return relative to the CRSP value-weighted index surrounding the most recent earnings announcement date up to the beginning of month $t$.

Data source: CRSP and I/B/E/S.

TAF: The time-series anchoring measure of FEPS based on the most recently announced EPS; TAF= $(F-F E P S$ - Last EPS)/LLast EPSI, where F-FEPS represents an individual firm's FEPS and Last EPS represents its most recently announced EPS.

Data source: I/B/E/S.

$C A P$

The industry cross-sectional anchoring measure of price levels; $C A P=($ F-Price $-I$-Price $) / I$ Pricel, where F-Price represents an individual firm's price level and I-Price represents the industry median of price levels. The 48 industries are defined as in Fama and French (1997) and the definition of 48 industries is available from Ken French's website.

Data source: CRSP and Fama and French (1997)

Experience: The natural logarithm of one plus the average number of months that the current group of analysts has been following the firm.

Data source: I/B/E/S.

Breadth: $\quad$ The natural logarithm of the average number of stocks followed by the current analysts. Data source: $\mathrm{I} / \mathrm{B} / \mathrm{E} / \mathrm{S}$.

Horizon: $\quad$ The natural logarithm of one plus the number of months before the next earnings announcement. Data source: $\mathrm{I} / \mathrm{B} / \mathrm{E} / \mathrm{S}$.

Inst_holding: The percentage of institutional ownership at the end of the previous quarter.

Data source: Thomson Reuters Institutional (13f) Holdings. 


\section{APPENDIX 2}

Historical Five-Year Growth of Earnings, Long-Term Growth Forecasts of Earnings, and Revisions of LongTerm Growth Forecasts for Portfolios Sorted by Size and CAF

This table reports the time-series averages of historical five-year growth rates of earnings $(F Y G)$, analysts' long-term growth forecasts of earnings $(L T G)$, and revisions in long-term growth forecasts $(R L T G)$ for $5 \times 5$ Size- and CAFsorted portfolios. At the beginning of each month, stocks are sorted into five groups (G1 to G5) based on the level of market capitalization (Size) at the end of the previous month. Stocks in each Size group are further sorted into five additional quintiles (E1 to E5) based on their $C A F$ in the previous month. The portfolios are held for twenty-four months after formation. FYG and $L T G$ are retrieved from the data in the previous month from $\mathrm{I} / \mathrm{B} / \mathrm{E} / \mathrm{S}$. $R L T G$ is estimated as the slope coefficient $\left(t_{i}\right)$ in the time-series simple regression of $L T G_{i, t}=a_{i}+t_{i}$ Time $_{t}+\varepsilon_{i, t}$ over the twenty-five months beginning from the previous month (at least twelve months), which measures the monthly movement of $L T G$. The sample selection criteria are the same as in Table 1. The sample period is from January 1983 to December 2005. The $t$-statistics (in parentheses) for the E5-E1 hedge portfolios are assessed using the Newey and West (1987) procedure to adjust for serial correlations. ${ }^{a, b, c}$ indicate significance at the $1 \%$ and $5 \%$ levels, respectively.

\begin{tabular}{|c|c|c|c|c|c|c|}
\hline \multirow[b]{2}{*}{$C A F$ quintiles } & \multicolumn{5}{|c|}{ Size quintiles } & \multirow[b]{2}{*}{ All stocks } \\
\hline & G1 (Small) & $\mathrm{G} 2$ & G3 & G4 & G5 (Large) & \\
\hline \multicolumn{7}{|c|}{ Panel A: Historical five-year growth of earnings ( $F Y G$ in \%) } \\
\hline E1 (Low) & -1.507 & 3.174 & 7.626 & 11.400 & 13.055 & 6.750 \\
\hline $\mathrm{E} 2$ & 2.202 & 9.532 & 15.974 & 18.061 & 13.432 & 11.840 \\
\hline E3 & 9.357 & 15.505 & 16.398 & 15.272 & 11.489 & 13.604 \\
\hline $\mathrm{E} 4$ & 12.710 & 16.445 & 15.667 & 14.358 & 11.436 & 14.123 \\
\hline E5 (High) & 16.557 & 16.596 & 18.782 & 16.394 & 14.887 & 16.643 \\
\hline $\begin{array}{l}\text { E5-E1 } \\
\text { t-statistic }\end{array}$ & $\begin{array}{l}\mathbf{1 8 . 0 6 4}^{\mathrm{a}} \\
(9.77)\end{array}$ & $\begin{array}{c}13.422^{\mathrm{a}} \\
(9.11)\end{array}$ & $\begin{array}{l}11.156^{\mathrm{a}} \\
(6.88)\end{array}$ & $\begin{array}{l}4.994^{\mathrm{a}} \\
(2.61)\end{array}$ & $\begin{array}{c}1.831 \\
(0.96)\end{array}$ & $\begin{array}{c}9.894^{\mathrm{a}} \\
(9.34)\end{array}$ \\
\hline \multicolumn{7}{|c|}{ Panel B: Long-term growth forecasts of earnings ( $L T G$ in \%) } \\
\hline E1 (Low) & 22.742 & 24.621 & 23.348 & 21.539 & 19.440 & 22.338 \\
\hline E2 & 21.066 & 21.909 & 20.619 & 18.066 & 14.162 & 19.164 \\
\hline E3 & 18.697 & 18.536 & 16.900 & 14.343 & 12.226 & 16.141 \\
\hline E4 & 16.657 & 16.069 & 14.263 & 12.491 & 11.374 & 14.171 \\
\hline E5 (High) & 13.773 & 12.811 & 12.273 & 11.662 & 11.342 & 12.372 \\
\hline $\begin{array}{l}\text { E5-E1 } \\
\text { t-statistic }\end{array}$ & $\begin{array}{c}-8.969^{a} \\
(-9.44)\end{array}$ & $\begin{array}{l}-11.810^{a} \\
(-12.22)\end{array}$ & $\begin{array}{l}-11.075^{a} \\
(-14.41)\end{array}$ & $\begin{array}{c}-9.877^{\mathrm{a}} \\
(-14.59)\end{array}$ & $\begin{array}{c}\mathbf{- 8 . 0 9 8}^{\mathrm{a}} \\
(-8.16)\end{array}$ & $\begin{array}{l}-9.966^{a} \\
(-9.88)\end{array}$ \\
\hline \multicolumn{7}{|c|}{ Panel C: Revisions in long-term growth forecasts of earnings ( $R L T G$ in \%) } \\
\hline E1 (Low) & -0.103 & -0.131 & -0.126 & -0.118 & -0.089 & -0.113 \\
\hline E2 & -0.107 & -0.136 & -0.114 & -0.082 & -0.043 & -0.096 \\
\hline E3 & -0.092 & -0.089 & -0.067 & -0.049 & -0.029 & -0.065 \\
\hline E4 & -0.067 & -0.062 & -0.043 & -0.033 & -0.024 & -0.046 \\
\hline E5 (High) & -0.052 & -0.039 & -0.036 & -0.030 & -0.023 & -0.036 \\
\hline $\begin{array}{l}\text { E5-E1 } \\
\text { t-statistic }\end{array}$ & $\begin{array}{c}\mathbf{0 . 0 5 0}^{\mathrm{b}} \\
(\mathbf{2 . 2 5})\end{array}$ & $\begin{array}{c}0.092^{\mathrm{a}} \\
(4.13)\end{array}$ & $\begin{array}{c}0.090^{\mathrm{a}} \\
(3.46)\end{array}$ & $\begin{array}{c}\mathbf{0 . 0 8 8}^{\mathrm{a}} \\
(5.18)\end{array}$ & $\begin{array}{c}0.067^{\mathrm{a}} \\
(3.16)\end{array}$ & $\begin{array}{c}0.077^{\mathrm{a}} \\
(\mathbf{3 . 6 4})\end{array}$ \\
\hline
\end{tabular}




\section{APPENDIX 3 \\ Returns on Portfolios Sorted by Size and CAF}

This table reports returns on $C A F$-sorted portfolios within each of five Size groups. At the beginning of each month, stocks are sorted into five groups (G1 to G5) based on the level of their market capitalization (Size) at the end of the previous month. Stocks in each Size group are further sorted into five additional quintiles (E1 to E5) based on their $C A F$ in the previous month. After the portfolio formation, both equally weighted $\left(E_{R e t_{0: 1}}\right)$ and value-weighted $\left(V \operatorname{Ret}_{0: 1}\right)$ one-month raw returns are calculated for each portfolio. The sample selection criteria are the same as in Table 1. The sample period is from January 1983 to December 2005. The $t$-statistics (in parentheses) for the E5-E1 hedge portfolios are assessed using the Newey and West (1987) procedure to adjust for serial correlations. ${ }^{\text {a,b,c }}$ indicate significance at the $1 \%, 5 \%$ and $10 \%$ levels, respectively.

\begin{tabular}{|c|c|c|c|c|c|c|}
\hline \multirow[b]{2}{*}{ CAF quintiles } & \multicolumn{5}{|c|}{ Size quintiles } & \multirow[b]{2}{*}{ All stocks } \\
\hline & G1 (Small) & $\mathrm{G} 2$ & G3 & G4 & G5 (Large) & \\
\hline \multicolumn{7}{|c|}{ Panel A: Equally weighted one-month raw returns (ERet $\left.t_{0: 1}\right)$} \\
\hline E1 (Low) & 0.253 & 0.512 & 0.682 & 0.786 & 0.954 & 0.637 \\
\hline E2 & 1.002 & 1.123 & 1.192 & 1.193 & 1.071 & 1.116 \\
\hline E3 & 1.250 & 1.399 & 1.354 & 1.204 & 1.202 & 1.282 \\
\hline E4 & 1.621 & 1.435 & 1.422 & 1.335 & 1.314 & 1.425 \\
\hline E5 (High) & 1.661 & 1.647 & 1.531 & 1.310 & 1.274 & 1.485 \\
\hline $\begin{array}{l}\text { E5 - E1 } \\
\text { t-statistic }\end{array}$ & $\begin{array}{l}1.408^{\mathrm{a}} \\
(6.11)\end{array}$ & $\begin{array}{l}1.135^{\mathrm{a}} \\
(\mathbf{3 . 6 3})\end{array}$ & $\begin{array}{l}{ }^{0.849^{\mathrm{a}}} \\
(\mathbf{2 . 6 8})\end{array}$ & $\begin{array}{l}\mathbf{0 . 5 2 4}^{\mathrm{b}} \\
(\mathbf{2 . 0 7})\end{array}$ & $\begin{array}{l}\mathbf{0 . 3 2 0 ^ { \mathrm { c } }} \\
(\mathbf{1 . 9 0 )}\end{array}$ & $\begin{array}{l}\mathbf{0 . 8 4 7}^{\mathrm{a}} \\
(\mathbf{3 . 7 0})\end{array}$ \\
\hline \multicolumn{7}{|c|}{ Panel B: Value-weighted one-month Raw returns (VRet $t_{0: 1}$ ) } \\
\hline E1 (Low) & 0.256 & 0.497 & 0.663 & 0.789 & 0.937 & 0.628 \\
\hline E2 & 0.975 & 1.118 & 1.184 & 1.188 & 1.031 & 1.099 \\
\hline E3 & 1.240 & 1.376 & 1.330 & 1.183 & 1.116 & 1.249 \\
\hline E4 & 1.622 & 1.407 & 1.423 & 1.308 & 1.212 & 1.395 \\
\hline E5 (High) & 1.655 & 1.645 & 1.500 & 1.279 & 1.168 & 1.449 \\
\hline $\begin{array}{l}\text { E5 - E1 } \\
\text { t-statistic }\end{array}$ & $\begin{array}{l}1.399^{\mathrm{a}} \\
(5.67)\end{array}$ & $\begin{array}{l}1.148^{\mathrm{a}} \\
(3.58)\end{array}$ & $\begin{array}{l}0.837^{\mathrm{a}} \\
(\mathbf{2 . 6 1})\end{array}$ & $\begin{array}{c}\mathbf{0 . 4 8 9}^{\mathrm{c}} \\
(1.95)\end{array}$ & $\begin{array}{c}0.231 \\
(1.23)\end{array}$ & $\begin{array}{l}\mathbf{0 . 8 2 1}^{\mathrm{a}} \\
(\mathbf{3 . 5 1})\end{array}$ \\
\hline
\end{tabular}


TABLE 1

\section{Summary Statistics}

This table reports descriptive statistics for the final sample during the period from January 1983 to December 2005. The sample includes all stocks listed on the NYSE, AMEX and Nasdaq, excluding stocks with prices less than \$5 at the end of the previous month. In addition, a stock is eligible to be included only if there are sufficient data in the CRSP, Compustat and I/B/E/S databases to compute the firm characteristics defined in Appendix 1. The time-series averages of common statistics for the major dependent and independent variables are reported.

\begin{tabular}{l|cccccc}
\hline Variables & Mean & Median & $\begin{array}{c}\text { Standard } \\
\text { deviation }\end{array}$ & Skewness & Percentile 10\% & Percentile 90\% \\
\hline CAF & 0.150 & 0.000 & 2.673 & 0.816 & -0.882 & 1.499 \\
F-FEPS (\$) & 1.592 & 1.327 & 1.533 & 1.125 & 0.157 & 3.420 \\
FE & 0.604 & 0.026 & 4.924 & 17.099 & -0.156 & 1.100 \\
BHAR $0: 1(\%)$ & 1.190 & 0.725 & 11.715 & 0.636 & -11.510 & 14.252 \\
ECAR $(\%)$ & 0.118 & 0.041 & 6.913 & 0.156 & -6.942 & 7.347 \\
Split & 0.008 & 0.000 & 0.087 & 12.56 & 0.000 & 0.000 \\
Size $(\$ B)$ & 2.028 & 0.351 & 6.277 & 5.816 & 0.060 & 4.082 \\
BTM & 0.688 & 0.599 & 0.465 & 1.711 & 0.213 & 1.242 \\
Ret $-6: 0(\%)$ & 10.814 & 6.964 & 31.356 & 1.186 & -22.062 & 46.072 \\
Accruals & -0.027 & -0.034 & 0.086 & 0.577 & -0.116 & 0.071 \\
ES $_{\text {recent }}(\%)$ & 0.292 & 0.112 & 6.883 & 0.404 & -6.731 & 7.571 \\
E/P $_{t-1}$ & 0.008 & 0.003 & 0.042 & 1.539 & -0.036 & 0.054 \\
\hline
\end{tabular}


TABLE 2

Correlations among Major Variables

This table reports the correlation coefficients between major dependent and independent variables. The final sample covers January 1983 to December 2005 . The sample includes all stocks listed on the NYSE, AMEX and Nasdaq, excluding stocks with prices less than $\$ 5$ at the end of the previous month. In addition, to be included in the sample a stock must have sufficient data in the CRSP, Compustat and I/B/E/S databases to compute the firm characteristics defined in Appendix

1. Time-series average correlation coefficients are reported in this table. ${ }^{\mathrm{a}, \mathrm{b}, \mathrm{c}}$ indicate significance at the $1 \%, 5 \%$ and $10 \%$ levels, respectively.

\begin{tabular}{|c|c|c|c|c|c|c|c|c|c|c|c|c|}
\hline Variables & $C A F$ & $F-F E P S$ & $F E$ & BHAR & $E C A R$ & Split & Size & $B T M$ & $\operatorname{Ret}_{-6: 0}$ & Accrual & $E S_{\text {recent }}$ & $E / P_{t-1}$ \\
\hline$F-F E P S$ & $0.709^{\mathrm{a}}$ & 1.000 & & & & & & & & & & \\
\hline$F E$ & -0.016 & -0.040 & 1.000 & & & & & & & & & \\
\hline$B H A R_{0: 1}$ & 0.019 & 0.026 & -0.054 & 1.000 & & & & & & & & \\
\hline$E C A R$ & 0.013 & 0.018 & -0.046 & $0.180^{\mathrm{b}}$ & 1.000 & & & & & & & \\
\hline Split & 0.051 & $0.068^{\mathrm{c}}$ & -0.011 & 0.023 & 0.003 & 1.000 & & & & & & \\
\hline Size & $0.349^{\mathrm{a}}$ & $0.371^{\mathrm{a}}$ & -0.035 & 0.003 & 0.005 & 0.019 & 1.000 & & & & & \\
\hline BTM & -0.070 & 0.015 & 0.019 & 0.020 & 0.016 & -0.032 & $-0.091^{b}$ & 1.000 & & & & \\
\hline $\operatorname{Ret}_{-6: 0}$ & 0.035 & $0.038^{\mathrm{c}}$ & $-0.081^{b}$ & 0.019 & 0.024 & $0.079^{\mathrm{b}}$ & 0.021 & 0.079 & 1.000 & & & \\
\hline Accrual & 0.003 & -0.023 & 0.023 & -0.023 & -0.016 & 0.003 & $-0.070^{\mathrm{c}}$ & $-0.116^{\mathrm{c}}$ & -0.069 & 1.000 & & \\
\hline$E S_{\text {recent }}$ & 0.021 & 0.022 & -0.041 & 0.033 & 0.023 & 0.028 & 0.009 & 0.024 & $0.241^{\mathrm{a}}$ & -0.021 & 1.000 & \\
\hline$E / P_{t-1}$ & $0.335^{\mathrm{a}}$ & $0.329^{\mathrm{a}}$ & 0.015 & 0.010 & -0.001 & 0.006 & 0.058 & -0.042 & $-0.093^{\mathrm{c}}$ & $0.137^{\mathrm{a}}$ & -0.034 & 1.000 \\
\hline
\end{tabular}


TABLE 3

\section{Forecast Errors and Anchoring}

This table reports the results from the Fama-MacBeth regressions to test the incremental role of $C A F$ in explaining the cross section of forecast errors. The dependent variable is the forecast error $(F E)$, defined as the difference between a firm's FEPS in the previous month and the corresponding actual earnings per share (Actual) deflated by the absolute value of Actual. That is, FE $=($ FEPS - Actual $) /$ Actuall.

The explanatory variables include a constant (not reported), the cross-sectional anchoring measure of FEPS (CAF), the natural logarithm of market capitalization at $t-1(\operatorname{Ln}(\operatorname{Size}))$, the natural logarithm of the book-to-market ratio $(\operatorname{Ln}(B T M))$, the past six-month return $\left(\right.$ Ret $\left._{-6:-0}\right)$, accounting accruals (Accruals), the three-day abnormal return surrounding the most recent earnings announcement date up to the beginning of month $t\left(E S_{\text {recent }}\right)$, the historical earnings-to-price ratios $\left(E / P_{t-1}\right)$, the experience of analysts (Experience), the breadth of analysts $(B r e a d t h)$, and the natural logarithm of the time gap between the forecasts and the actual earnings announcements (Horizon). Their detailed definitions are provided in Appendix 1.

In Panel A, the Fama and Macbeth (1973) cross-sectional regressions are estimated each month from February 1983 to December 2005, and the means of the monthly estimates are reported. Stocks with a price less than $\$ 5$ are excluded from the sample. For all the dependent and explanatory variables, values greater than the 0.995 fractile or less than the 0.005 fractile are set to equal to the 0.995 and 0.005 fractile values, respectively.

Panel B of this table reports the time-series averages of forecast errors $(F E)$ for $5 \times 5$ Size- and $C A F$-sorted portfolios. The portfolios are constructed as follows: at the beginning of each month, all stocks are sorted into five groups (G1 to G5) based on their market capitalization (Size) at the end of the previous month. The stocks in each Size group are then further sorted into five quintiles (E1 to E5) based on their $C A F$ in the previous month.

The $t$-statistics reported in parentheses have been adjusted for serial correlation and heteroscedasticity using the Newey and West (1987) procedure. ${ }^{\mathrm{a}, \mathrm{b}, \mathrm{c}}$ indicate significance at the $1 \%, 5 \%$ and $10 \%$ levels, respectively. 
Table 3 - Continued

Panel A: Results from the Fama-MacBeth regressions of forecast errors

\begin{tabular}{|c|c|c|c|}
\hline & (1) & (2) & (3) \\
\hline $\boldsymbol{C A F}$ & $\begin{array}{l}-0.011^{b} \\
(-2.42)\end{array}$ & $\begin{array}{l}-0.012^{b} \\
(-2.54)\end{array}$ & $\begin{array}{l}-0.016^{a} \\
(-2.91)\end{array}$ \\
\hline $\log ($ Size $)$ & $\begin{array}{c}-0.114^{\mathrm{a}} \\
(-24.06)\end{array}$ & $\begin{array}{c}-0.111^{\mathrm{a}} \\
(-23.48)\end{array}$ & $\begin{array}{c}-0.109^{\mathrm{a}} \\
(-19.14)\end{array}$ \\
\hline $\log (B T M)$ & $\begin{array}{c}0.102^{\mathrm{a}} \\
(6.43)\end{array}$ & $\begin{array}{c}0.114^{\mathrm{a}} \\
(7.22)\end{array}$ & $\begin{array}{c}0.124^{\mathrm{a}} \\
(7.41)\end{array}$ \\
\hline $\operatorname{Ret}_{-6,0}$ & $\begin{array}{r}-0.009^{a} \\
(-16.34)\end{array}$ & $\begin{array}{c}-0.009^{\mathrm{a}} \\
(-15.56)\end{array}$ & $\begin{array}{c}-0.009^{\mathrm{a}} \\
(-15.58)\end{array}$ \\
\hline Accruals & & $\begin{array}{c}0.342^{\mathrm{a}} \\
(3.92)\end{array}$ & $\begin{array}{c}0.348^{\mathrm{a}} \\
(3.98)\end{array}$ \\
\hline$E S_{\text {recent }}$ & & $\begin{array}{l}-0.008^{\mathrm{a}} \\
(-7.51)\end{array}$ & $\begin{array}{l}-0.008^{a} \\
(-7.99)\end{array}$ \\
\hline$E / P_{t-1}$ & & & $\begin{array}{c}-0.034 \\
(-0.44)\end{array}$ \\
\hline Experience & & & $\begin{array}{c}0.020^{\mathrm{b}} \\
(2.44)\end{array}$ \\
\hline Breadth & & & $\begin{array}{l}-0.062^{\mathrm{a}} \\
(-5.00)\end{array}$ \\
\hline Horizon & & & $\begin{array}{r}0.322^{\mathrm{a}} \\
(24.18)\end{array}$ \\
\hline Average Adj. $R^{2}$ & 0.034 & 0.036 & 0.046 \\
\hline Avg. N/Year & 1,451 & 1,449 & 1,444 \\
\hline
\end{tabular}

Panel B: Forecast errors $(F E)$ for Size-and $C A F$-sorted portfolios

\begin{tabular}{|c|c|c|c|c|c|c|}
\hline \multirow[b]{2}{*}{$C A F$ quintiles } & \multicolumn{5}{|c|}{ Size quintiles } & \multirow[b]{2}{*}{ All stock } \\
\hline & G1 (Small) & G2 & G3 & G4 & G5 (Large) & \\
\hline E1 (Low) & 0.320 & 0.221 & 0.144 & 0.065 & 0.018 & 0.154 \\
\hline $\mathrm{E} 2$ & 0.229 & 0.082 & 0.031 & 0.013 & 0.005 & 0.072 \\
\hline E3 & 0.107 & 0.040 & 0.016 & 0.009 & 0.005 & 0.036 \\
\hline $\mathrm{E} 4$ & 0.072 & 0.036 & 0.012 & 0.004 & 0.006 & 0.026 \\
\hline E5 (High) & 0.068 & 0.034 & 0.015 & 0.009 & 0.002 & 0.026 \\
\hline $\begin{array}{l}\mathrm{E} 5-\mathrm{E} 1 \\
t \text {-statistic }\end{array}$ & $\begin{array}{l}-0.253^{\mathrm{a}} \\
(-5.82)\end{array}$ & $\begin{array}{c}-0.187^{a} \\
(-5.65)\end{array}$ & $\begin{array}{c}-0.129^{a} \\
(-5.40)\end{array}$ & $\begin{array}{c}-0.056^{a} \\
(-4.81)\end{array}$ & $\begin{array}{l}-0.016 \\
(-1.92)\end{array}$ & $\begin{array}{c}-0.128^{\mathrm{a}} \\
(-5.28)\end{array}$ \\
\hline
\end{tabular}


TABLE 4

\section{The Cross-section of Stock Returns and Anchoring}

Panel A of this table reports the results from the Fama-MacBeth regressions to test the incremental role of $C A F$ in explaining the cross section of individual stock returns. The dependent variable is the one-month raw return $\left(B H A R_{0: 1}\right)$ in the current month, $t$. The explanatory variables include a constant (not reported), the cross-sectional anchoring measure of FEPS $(C A F)$, the natural logarithm of market capitalization at $t-1(\operatorname{Ln}(\operatorname{Size}))$, the natural logarithm of the book-to-market ratio $(\operatorname{Ln}(B T M))$, a one-month lag of the past six-month return $\left(\operatorname{Ret}_{-7:-1}\right)$, the past

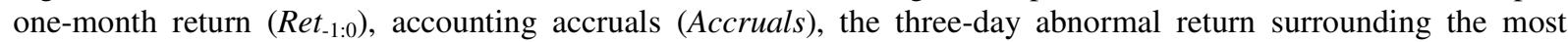
recent earnings announcement date up to the beginning of month $t\left(E S_{\text {recent }}\right)$, the historical earnings-to-price ratios $\left(E / P_{t-1}\right)$, and the time-series anchoring measure of FEPS $(T A F)$. Their detailed definitions are provided in Appendix 1.

Panel B reports the risk-adjusted returns (i.e., Alpha) for equal-weighted portfolios based on Size and CAF sorting. Alpha is the intercept term from the time-series regression based on the Fama and French plus Carhart four-factor model described in equation (2). The portfolios are constructed as follows. At the beginning of each month, stocks are sorted into five groups (G1 to G5) based on their market capitalization (Size) at the end of the previous month, and the stocks in each Size group are further sorted into five quintiles (E1 to E5) based on their CAF in the previous month.

The sample starts in February 1983 and ends in December 2005. Stocks with a price less than $\$ 5$ are excluded from the sample. For all the dependent and explanatory variables (except for stock returns), values greater than the 0.995 fractile or less than the 0.005 fractile are set to equal to the 0.995 and 0.005 fractile values, respectively. The $t$ statistics reported in parentheses are adjusted for serial correlation and heteroscedasticity using the Newey and West (1987) procedure. ${ }^{\text {a,b,c }}$ indicate significance at the $1 \%, 5 \%$ and $10 \%$ levels, respectively. 
Table 4 - Continued

Panel A: Results from the Fama-MacBeth regressions of stock returns

\begin{tabular}{|c|c|c|c|}
\hline & (1) & (2) & (3) \\
\hline$C A F$ & $\begin{array}{c}0.107^{a} \\
(3.43)\end{array}$ & $\begin{array}{c}\mathbf{0 . 1 1 1}^{\mathrm{a}} \\
(3.59)\end{array}$ & $\begin{array}{l}0^{0.093}{ }^{\mathrm{a}} \\
(3.46)\end{array}$ \\
\hline $\log ($ Size $)$ & $\begin{array}{c}-0.048 \\
(-0.95)\end{array}$ & $\begin{array}{c}-0.068 \\
(-1.39)\end{array}$ & $\begin{array}{c}-0.067 \\
(-1.35)\end{array}$ \\
\hline $\log (B T M)$ & $\begin{array}{c}0.248^{\mathrm{c}} \\
(1.92)\end{array}$ & $\begin{array}{c}0.191 \\
(1.51)\end{array}$ & $\begin{array}{c}0.183 \\
(1.45)\end{array}$ \\
\hline $\operatorname{Ret}_{-7:-1}$ & $\begin{array}{l}0.010^{\mathrm{a}} \\
(3.65)\end{array}$ & $\begin{array}{l}0.007^{\mathrm{a}} \\
(2.67)\end{array}$ & $\begin{array}{l}0.008^{\mathrm{a}} \\
(2.86)\end{array}$ \\
\hline $\operatorname{Ret}_{-1: 0}$ & $\begin{array}{l}-0.027^{\mathrm{a}} \\
(-4.78)\end{array}$ & $\begin{array}{l}-0.034^{\mathrm{a}} \\
(-5.94)\end{array}$ & $\begin{array}{l}-0.033^{\mathrm{a}} \\
(-5.94)\end{array}$ \\
\hline Accruals & & $\begin{array}{l}-2.444^{\mathrm{a}} \\
(-6.38)\end{array}$ & $\begin{array}{l}-2.664^{\mathrm{a}} \\
(-7.09)\end{array}$ \\
\hline$E S_{\text {recent }}$ & & $\begin{array}{c}0.054^{\mathrm{a}} \\
(12.55)\end{array}$ & $\begin{array}{c}0.054^{\mathrm{a}} \\
(12.67)\end{array}$ \\
\hline$E / P_{t-1}$ & & & $\begin{array}{l}1.350^{\mathrm{a}} \\
(2.63)\end{array}$ \\
\hline Avg. Adj. $R^{2}$ & 0.043 & 0.046 & 0.048 \\
\hline Avg. N/Year & 1,893 & 1,891 & 1,889 \\
\hline
\end{tabular}

Panel B: Alphas based on the Fama-French and Carhart four-factor model for Size- and CAF-sorted portfolios

\begin{tabular}{|c|c|c|c|c|c|c|}
\hline \multirow[b]{2}{*}{ CAF quintiles } & \multicolumn{5}{|c|}{ Size quintiles } & \multirow[b]{2}{*}{ All stocks } \\
\hline & G1 (Small) & G2 & G3 & G4 & G5 (Large) & \\
\hline E1 (Low) & -0.757 & -0.455 & -0.432 & -0.306 & -0.197 & -0.449 \\
\hline $\mathrm{E} 2$ & -0.165 & -0.119 & -0.072 & -0.019 & -0.070 & -0.089 \\
\hline E3 & 0.063 & 0.195 & 0.133 & -0.072 & 0.080 & 0.080 \\
\hline $\mathrm{E} 4$ & 0.461 & 0.199 & 0.142 & 0.104 & 0.054 & 0.192 \\
\hline E5 (High) & 0.662 & 0.416 & 0.313 & 0.117 & 0.152 & 0.312 \\
\hline $\begin{array}{l}\mathrm{E} 5-\mathrm{E} 1 \\
t \text {-statistic }\end{array}$ & $\begin{array}{c}1.419^{\mathrm{a}} \\
(7.12)\end{array}$ & $\begin{array}{c}\text { 0.871 }^{\mathrm{a}} \\
(\mathbf{3 . 8 3})\end{array}$ & $\begin{array}{c}0.745^{\mathrm{a}} \\
(3.27)\end{array}$ & $\begin{array}{l}0^{0.423^{b}} \\
(2.18)\end{array}$ & $\begin{array}{c}\mathbf{0 . 3 4 9}^{\mathrm{b}} \\
(2.37)\end{array}$ & $\begin{array}{c}0.761^{\mathrm{a}} \\
(4.75)\end{array}$ \\
\hline
\end{tabular}


TABLE 5

\section{Ex-post Earnings Announcement Effects and Anchoring}

Panel A of this table reports the results from the Fama-MacBeth regressions to test the incremental role of $C A F$ in explaining the cross section of ex-post earnings announcement effects. The dependent variable is the earnings announcement return $(E C A R)$, which is defined as the cumulative three-day abnormal return relative to the CRSP value-weighted index surrounding the next earnings announcement day after portfolio formation over the next twelve months. The explanatory variables include a constant (not reported), the cross-sectional anchoring measure of FEPS $(C A F)$, the natural logarithm of market capitalization at $t-1(\operatorname{Ln}(\operatorname{Size}))$, the natural logarithm of the book-tomarket ratio $(\operatorname{Ln}(B T M))$, the past six-month return (Ret $-6:-0)$, accounting accruals (Accruals), the three-day abnormal return surrounding the most recent earnings announcement date up to the beginning of month $t\left(E S_{\text {recent }}\right)$, the historical earnings-to-price ratios $\left(E / P_{t-1}\right)$, and the time-series anchoring measure of $F E P S(T A F)$. Their detailed definitions are provided in Appendix 1. For all dependent and explanatory variables (except for stock returns), values greater than the 0.995 fractile or less than the 0.005 fractile are set to equal to the 0.995 and 0.005 fractile values, respectively. The $t$-statistics reported in parentheses are adjusted for serial correlation and heteroscedasticity using the Newey and West (1987) procedure.

Panel B of this table reports the time-series averages of the means of earnings announcement returns $(E C A R)$ for the $5 \times 5$ Size- and $C A F$-sorted portfolios. At the beginning of each month, all stocks are sorted into five groups (G1 to G5) based on their market capitalization (Size) at the end of the previous month. Stocks in each Size group are further sorted into five quintiles (E1 to E5) based on their $C A F$ in the previous month. The portfolios are held for twelve months after formation.

The sample starts in February 1983 and ends in December 2005. Stocks with a price less than $\$ 5$ are excluded from the sample. ${ }^{\mathrm{a}, \mathrm{b}, \mathrm{c}}$ indicate significance at the $1 \%, 5 \%$ and $10 \%$ levels, respectively. 


\section{Table 5 - Continued}

Panel A: Results from the Fama-MacBeth regressions of ECAR

\begin{tabular}{|c|c|c|c|}
\hline & (1) & (2) & (3) \\
\hline$C A F$ & $\begin{array}{c}0.041^{\mathrm{a}} \\
(4.20)\end{array}$ & $\begin{array}{c}0.042^{\mathrm{a}} \\
(4.36)\end{array}$ & $\begin{array}{c}0.050^{\mathrm{a}} \\
(4.77)\end{array}$ \\
\hline $\log ($ Size $)$ & $\begin{array}{c}0.039^{\mathrm{a}} \\
(2.78)\end{array}$ & $\begin{array}{l}0.032^{b} \\
(2.30)\end{array}$ & $\begin{array}{l}0.032^{\mathrm{b}} \\
(2.24)\end{array}$ \\
\hline $\log (B T M)$ & $\begin{array}{c}0.194^{\mathrm{a}} \\
(6.69)\end{array}$ & $\begin{array}{c}0.174^{\mathrm{a}} \\
(6.23)\end{array}$ & $\begin{array}{l}0.175^{\mathrm{a}} \\
(6.32)\end{array}$ \\
\hline $\operatorname{Ret}_{-6:-0}$ & $\begin{array}{c}0.005^{\mathrm{a}} \\
(5.61)\end{array}$ & $\begin{array}{c}0.004^{\mathrm{a}} \\
(4.81)\end{array}$ & $\begin{array}{l}0.004^{\mathrm{a}} \\
(5.07)\end{array}$ \\
\hline Accruals & & $\begin{array}{l}-0.860^{\mathrm{a}} \\
(-4.23)\end{array}$ & $\begin{array}{l}-0.863^{\mathrm{a}} \\
(-4.26)\end{array}$ \\
\hline$E S_{\text {recent }}$ & & $\begin{array}{c}0.017^{\mathrm{a}} \\
(5.75)\end{array}$ & $\begin{array}{c}0.017^{\mathrm{a}} \\
(5.46)\end{array}$ \\
\hline$E / P_{t-1}$ & & & $\begin{array}{c}-0.013 \\
(-0.06)\end{array}$ \\
\hline Avg. Adj. $R^{2}$ & 0.004 & 0.005 & 0.005 \\
\hline Avg. N/Year & 1,916 & 1,914 & 1,911 \\
\hline
\end{tabular}

Panel B: Ex-post earnings announcement effects (ECAR) for Size- and CAF-sorted portfolios

\begin{tabular}{lcccccc}
\hline & \multicolumn{7}{c}{ Size quintiles } \\
\cline { 2 - 6 } CAF quintiles & G1 (Small) & G2 & G3 & G4 & G5 (Large) & All stocks \\
\hline E1 (Low) & -0.248 & -0.456 & -0.208 & 0.054 & 0.105 & -0.151 \\
E2 & 0.069 & 0.009 & 0.016 & 0.206 & 0.186 & 0.097 \\
E3 & 0.145 & 0.103 & 0.211 & 0.148 & 0.223 & 0.166 \\
E4 & 0.305 & 0.192 & 0.247 & 0.312 & 0.208 & 0.253 \\
E5 (High) & 0.259 & 0.142 & 0.153 & 0.345 & 0.220 & 0.224 \\
\hline E5-E1 & $\mathbf{0 . 5 0 7}$ & $\mathbf{0 . 5 9 8}$ & $\mathbf{0 . 3 6 1}$ & $\mathbf{0 . 2 9 2}$ & $\mathbf{0 . 1 1 5}$ & $\mathbf{0 . 3 7 4}$ \\
t-statistic & $\mathbf{( 5 . 0 7 )}$ & $\mathbf{( 5 . 1 3 )}$ & $\mathbf{( 3 . 2 1 )}$ & $\mathbf{( 1 . 4 2 )}$ & $\mathbf{( 1 . 1 6 )}$ & $(\mathbf{6 . 7 1 )}$
\end{tabular}




\section{TABLE 6}

\section{Stock Splits and Anchoring}

Panel A reports the results from the logit regressions testing the likelihood of a stock split. The dependent variable is a dummy variable that equals one if a firm carries out a significant stock split (i.e., one share is split into 1.5 or more shares) in month $t$ and zero otherwise. The explanatory variables include a constant (not reported), the crosssectional anchoring measure of $F E P S(C A F)$, the natural logarithm of market capitalization at $t-1(\operatorname{Ln}(\operatorname{Size}))$, the natural logarithm of the book-to-market ratio $(\operatorname{Ln}(B T M))$, the past six-month return $\left(\right.$ Ret $\left._{-6:-0}\right)$, accounting accruals (Accruals), the three-day abnormal return surrounding the most recent earnings announcement date up to the beginning of month $t\left(E S_{\text {recent }}\right)$, the historical earnings-to-price ratios $\left(E / P_{t-1}\right)$, and the time-series anchoring measure of FEPS $(T A F)$. Their detailed definitions are provided in Appendix 1. The $\mathrm{z}$-statistics reported in parentheses have been adjusted for clustered standard errors at both the firm level and the time level (as proposed by Petersen (2009)).

Panel B reports the time-series averages of stock-split ratios $(S S R)$ for $5 \times 5$ Size- and $C A F$-sorted portfolios. At the beginning of each month, all stocks are sorted into five groups (G1 to G5) based on their market capitalization (Size) at the end of the previous month. The stocks in each Size group are further sorted into five quintiles (E1 to E5) based on their $C A F$ in the previous month. The portfolios are held for twelve months after formation. The stock-split ratio $(S S R)$ is defined as the cumulative stock-split-driven (with CRSP Item DISTCD's first digit equals 5) changes of the factor to adjust shares outstanding (CRSP Item FACSHR) in the following twelve months. The $t$-statistics reported in Panel B have been adjusted for serial correlation and heteroscedasticity using the Newey and West (1987) procedure.

The sample starts in February 1983 and ends in December 2005. Stocks with a price less than $\$ 5$ are excluded from the sample. ${ }^{\mathrm{a}, \mathrm{b}, \mathrm{c}}$ indicate significance at the $1 \%, 5 \%$ and $10 \%$ levels, respectively. 


\section{Table 6 - Continued}

Panel A: Results from the likelihood logit regressions of a stock split

\begin{tabular}{|c|c|c|c|}
\hline & (1) & $(2)$ & (3) \\
\hline \multirow[t]{2}{*}{$C A F$} & $0.008^{a}$ & $0.007^{a}$ & $0.006^{b}$ \\
\hline & (2.86) & (2.76) & (2.59) \\
\hline \multirow[t]{2}{*}{$\log ($ Size $)$} & $0.050^{\mathrm{a}}$ & $0.080^{\mathrm{a}}$ & $0.067^{\mathrm{a}}$ \\
\hline & $(4.15)$ & $(5.49)$ & $(4.54)$ \\
\hline \multirow[t]{2}{*}{$\log (B T M)$} & $-0.174^{\mathrm{a}}$ & $-0.224^{\mathrm{a}}$ & $-0.239^{\mathrm{a}}$ \\
\hline & $(-8.78)$ & $(-9.46)$ & $(-9.91)$ \\
\hline \multirow[t]{2}{*}{$\operatorname{Ret}_{-6:-0}$} & $0.008^{\mathrm{a}}$ & $0.008^{\mathrm{a}}$ & $0.008^{\mathrm{a}}$ \\
\hline & $(6.67)$ & $(6.21)$ & $(6.06)$ \\
\hline \multirow[t]{2}{*}{$E S_{\text {recent }}$} & & $0.016^{\mathrm{a}}$ & $0.017^{\mathrm{a}}$ \\
\hline & & $(9.55)$ & (9.97) \\
\hline \multirow[t]{2}{*}{ Accruals } & & $1.146^{\mathrm{a}}$ & $0.918^{\mathrm{a}}$ \\
\hline & & $(6.73)$ & $(5.29)$ \\
\hline \multirow[t]{2}{*}{$E / P_{t-1}$} & & & $2.304^{\mathrm{a}}$ \\
\hline & & & $(8.03)$ \\
\hline \multirow[t]{2}{*}{$T A F$} & & & 0.009 \\
\hline & & & $(0.65)$ \\
\hline
\end{tabular}

Pseudo $R^{2}$

0.027

$\mathbf{0 . 0 3 5}$

0.037

Panel B: Stock split ratios (SSR) for Size- and $C A F$-sorted portfolios

\begin{tabular}{|c|c|c|c|c|c|c|}
\hline \multirow[b]{2}{*}{$C A F$ quintiles } & \multicolumn{5}{|c|}{ Size quintiles } & \multirow[b]{2}{*}{ All stocks } \\
\hline & G1 (Small) & $\mathrm{G} 2$ & G3 & G4 & G5 (Large) & \\
\hline E1 (Low) & 1.009 & 1.017 & 1.025 & 1.062 & 1.103 & 1.043 \\
\hline $\mathrm{E} 2$ & 1.018 & 1.031 & 1.057 & 1.082 & 1.082 & 1.054 \\
\hline E3 & 1.028 & 1.058 & 1.085 & 1.092 & 1.096 & 1.072 \\
\hline E4 & 1.049 & 1.077 & 1.100 & 1.112 & 1.132 & 1.094 \\
\hline E5 (High) & 1.107 & 1.142 & 1.182 & 1.201 & 1.269 & 1.180 \\
\hline E5-E1 & $0.098^{\mathrm{a}}$ & $0.126^{a}$ & $0.157^{a}$ & $0.139^{a}$ & $0.166^{\mathrm{a}}$ & $0.137^{\mathrm{a}}$ \\
\hline t-statistic & (9.31) & (11.23) & (10.43) & (7.69) & (4.87) & (8.48) \\
\hline
\end{tabular}


TABLE 7

Earnings Forecast Revisions, Forecast Errors, and Changes in Earnings Surprises after Stock Splits for Size- and CAF-sorted Portfolios

This table presents the results for the differences in the earnings forecast revisions (Panel A), forecast errors (Panel $\mathrm{B})$ and the changes in abnormal returns surrounding earnings announcement dates (Panel C) between firms which split their stocks and a matching group of firms which do not. In the tests reported in Panels A and B, stock-split firms are matched with no-split firms similar in size, book-to-market ratio, forecast errors before the split, and $C A F$. Differences in forecast errors and in forecast revisions between the split firms and the median of the matching nosplit firms are computed. In Panel $\mathrm{C}$, for each firm and each month, the change in ex-post and ex-ante abnormal returns surrounding earnings announcement date $\left(\mathrm{ES}_{\text {next }}-\mathrm{ES}_{\text {recent }}\right)$ are calculated. We report the difference in $\left(\mathrm{ES}_{\text {next }}{ }^{-}\right.$ $\left.\mathrm{ES}_{\text {recent }}\right)$ between split firms and the median of the matching no-split firms.

The sample starts in February 1983 and ends in December 2005. Stocks with a price less than $\$ 5$ are excluded from the sample. ${ }^{\mathrm{a}, \mathrm{b}, \mathrm{c}}$ indicate significance at the $1 \%, 5 \%$ and $10 \%$ levels, respectively.

\begin{tabular}{|c|c|c|c|c|c|c|}
\hline \multirow[b]{2}{*}{$C A F$ quintiles } & \multicolumn{5}{|c|}{ Size quintiles } & \multirow[b]{2}{*}{ All stocks } \\
\hline & G1 (Small) & G2 & G3 & G4 & G5 (Large) & \\
\hline \multicolumn{7}{|c|}{ Panel A: Differences in ex-post average forecast revisions between split firms and no-split firms } \\
\hline E1 (Low) & 0.086 & 0.101 & 0.072 & 0.073 & 0.055 & 0.075 \\
\hline E2 & 0.069 & 0.038 & 0.043 & 0.043 & 0.049 & 0.046 \\
\hline E3 & 0.016 & 0.033 & 0.035 & 0.031 & 0.030 & 0.031 \\
\hline $\mathrm{E} 4$ & -0.003 & 0.022 & 0.023 & 0.021 & 0.022 & 0.021 \\
\hline E5 (High) & -0.009 & 0.007 & 0.027 & 0.005 & 0.011 & 0.011 \\
\hline All stocks & $0.036^{\mathrm{a}}$ & $0.035^{\mathrm{a}}$ & $0.035^{a}$ & $0.027^{\mathrm{a}}$ & $0.024^{a}$ & $0.029^{a}$ \\
\hline t-statistic & $(4.55)$ & $(6.21)$ & $(8.79)$ & $(8.90)$ & $(\mathbf{8 . 3 0})$ & (16.78) \\
\hline \multicolumn{7}{|c|}{ Panel B: Differences in ex-post forecast errors $(F E)$ between split firms and no-split firms } \\
\hline E1 (Low) & 0.080 & 0.022 & 0.153 & 0.124 & 0.073 & 0.095 \\
\hline E2 & 0.062 & 0.023 & 0.012 & 0.026 & 0.041 & 0.028 \\
\hline E3 & 0.023 & 0.028 & -0.012 & 0.010 & 0.015 & 0.011 \\
\hline E4 & -0.016 & -0.007 & 0.023 & 0.010 & 0.007 & 0.008 \\
\hline E5 (High) & -0.028 & -0.009 & -0.007 & -0.004 & 0.004 & -0.001 \\
\hline All stocks & $0.032^{b}$ & 0.015 & $0.014^{b}$ & $0.017^{\mathrm{a}}$ & $0.014^{a}$ & $0.017^{\mathrm{a}}$ \\
\hline t-statistic & (1.96) & (1.54) & $(2.04)$ & (3.65) & (3.13) & $(5.53)$ \\
\hline \multicolumn{7}{|c|}{ Panel C: Differences in ex-post earning surprises $(E S)$ between split firms and no-split firms } \\
\hline E1 (Low) & -6.033 & -5.344 & -5.576 & -0.440 & 0.110 & -2.738 \\
\hline E2 & -4.537 & -4.129 & -2.360 & -3.125 & -1.152 & -3.091 \\
\hline E3 & -3.415 & -2.764 & -1.770 & -0.890 & -2.420 & -2.013 \\
\hline $\mathrm{E} 4$ & -2.315 & -2.820 & -2.035 & -1.542 & -1.858 & -2.006 \\
\hline E5 (High) & -2.077 & -0.843 & -0.549 & -1.622 & -1.118 & -1.170 \\
\hline All stocks & $-3.339^{a}$ & $-2.611^{a}$ & $-1.578^{a}$ & $-1.568^{a}$ & $-1.321^{\mathrm{a}}$ & $-1.778^{a}$ \\
\hline t-statistic & $(-6.23)$ & $(-6.80)$ & $(-5.48)$ & $(-6.01)$ & $(-5.54)$ & $(-13.04)$ \\
\hline
\end{tabular}


TABLE 8

\section{Robustness Checks within Sub-groups}

The regression tests in Panel A of Tables 3, 4 and 5 are repeated in sub-groups defined as follows. In each month, the entire sample is divided into two equal sub-groups based on the stability of the anchor, the average size of analyst-affiliated brokers or institutional holdings. The anchor is the median I-FEPS within each of the 48 industries. The stability of the anchor is measured by the coefficient of variation of I-FEPS $(C V)$ over the previous 24 months (a lower $C V$ indicates a more stable anchor). Broker size is measured by the number of active analysts affiliated to the broker at the end of the previous month. The institutional holding is the percentage of institutional ownership at the end of the previous quarter (Inst_holding).

The sample for sub-groups based on the stability of the anchor starts in February 1985 and ends in December 2005. The other sub-group tests start in February 1983 and end in December 2005. Stocks with prices less than $\$ 5$ are excluded from the sample. For simplicity, only the coefficients and $t$-statistics of $C A F$ are reported. The differences in the coefficients and their $t$-statistics between the two subgroups are also reported. All $t$-statistics reported in parentheses are adjusted for serial correlation and heteroscedasticity using the Newey and West (1987) procedure. a,b,c indicate significance at the $1 \%, 5 \%$ and $10 \%$ levels, respectively.

\begin{tabular}{|c|c|c|c|c|}
\hline \multicolumn{5}{|c|}{ Panel A: Forecast errors $(F E)$} \\
\hline & Stable anchor & Unstable anchor & Small brokers & Large brokers \\
\hline$C A F$ & $-0.058^{\mathrm{a}}$ & $-0.010^{c}$ & $-0.027^{\mathrm{a}}$ & $-0.019^{\mathrm{a}}$ \\
\hline$t$-statistic & $(-8.40)$ & $(-1.67)$ & $(-3.69)$ & $(3.57)$ \\
\hline Difference & \multicolumn{2}{|c|}{$-0.048^{\mathrm{a}}$} & \multicolumn{2}{|c|}{$-0.008^{c}$} \\
\hline$t$-statistic & \multicolumn{2}{|c|}{$(-5.61)$} & \multicolumn{2}{|c|}{$(-1.78)$} \\
\hline \multicolumn{5}{|c|}{ Panel B: Future stock returns $\left(B H A R_{0,1}\right)$} \\
\hline & Stable anchor & Unstable anchor & Low inst. holding & High inst. holding \\
\hline$C A F$ & $0.120^{\mathrm{b}}$ & $0.075^{\mathrm{b}}$ & $0.168^{\mathrm{a}}$ & $0.041^{\mathrm{c}}$ \\
\hline$t$-statistic & $(2.36)$ & $(2.45)$ & $(4.24)$ & $(1.67)$ \\
\hline Difference & \multicolumn{2}{|c|}{$0.045^{b}$} & \multicolumn{2}{|c|}{$0.127^{\mathrm{a}}$} \\
\hline$t$-statistic & \multicolumn{2}{|c|}{$(\mathbf{1 . 9 7})$} & \multicolumn{2}{|c|}{$(4.03)$} \\
\hline \multicolumn{5}{|c|}{ Panel C: Ex-post earning announcement returns (ECAR) } \\
\hline & Stable anchor & Unstable anchor & Low inst. holding & High inst. holding \\
\hline$C A F$ & $0.099^{\mathrm{a}}$ & $0.038^{\mathrm{a}}$ & $0.073^{\mathrm{a}}$ & $0.022^{\mathrm{b}}$ \\
\hline$t$-statistic & $(3.96)$ & $(2.89)$ & $(3.61)$ & $(1.99)$ \\
\hline Difference & \multicolumn{2}{|c|}{$0.061^{b}$} & \multicolumn{2}{|c|}{$0.051^{b}$} \\
\hline$t$-statistic & \multicolumn{2}{|c|}{$(2.27)$} & \multicolumn{2}{|c|}{$(2.44)$} \\
\hline
\end{tabular}


TABLE 9

\section{Robustness Checks with Alternative Anchors}

Panel A (panel B) of this table reports the risk-adjusted returns (i.e., Alpha) for equal-weighted portfolios based on Size and $C A P(T A F) . C A P$ is the industry cross-sectional anchoring measure of stock price, defined as the difference between the price level of a firm (F-Price) and the industry median price level (I-Price), scaled by the absolute value of the latter. TAF is the time-series anchoring measure of forecasted $E P S$, defined as the difference between the forecasted EPS of a firm (F-FEPS) and the most recently announced actual EPS, scaled by the absolute value of the latter. Alpha is the intercept term from the time-series regression based on the Fama and French plus Carhart four-factor model as described in equation (2). The portfolios are constructed as follows. At the beginning of each month, stocks are sorted into five groups (G1 to G5) based on their market capitalization (Size) at the end of the previous month, and the stocks in each Size group are further sorted into five quintiles (E1 to E5) based on their CAP $(T A F)$ in the previous month. The sample starts in February 1983 and ends in December 2005. Stocks with a price less than $\$ 5$ are excluded from the sample. The $t$-statistics reported in parentheses are adjusted for serial correlation and heteroscedasticity using the Newey and West (1987) procedure. ${ }^{\text {a,b, }}$ indicate significance at the $1 \%$, $5 \%$ and $10 \%$ levels, respectively.

\begin{tabular}{lcccccc}
\hline Panel A & \multicolumn{5}{c}{ Size quintiles } & \\
\cline { 2 - 6 } CAP quintiles & G1 (Small) & $\mathrm{G} 2$ & $\mathrm{G} 3$ & $\mathrm{G} 4$ & $\mathrm{G} 5$ (Large) & All stocks \\
\hline E1 (Low) & -0.051 & -0.028 & -0.073 & 0.044 & 0.096 & -0.003 \\
E2 & -0.142 & 0.151 & 0.099 & -0.062 & -0.026 & 0.004 \\
E3 & -0.001 & 0.026 & -0.021 & 0.035 & -0.057 & -0.004 \\
E4 & 0.111 & 0.026 & 0.096 & -0.195 & -0.052 & -0.003 \\
E5 (High) & 0.152 & 0.074 & -0.022 & 0.007 & 0.065 & 0.055 \\
E5 - E1 & $\mathbf{0 . 2 0 3}$ & $\mathbf{0 . 1 0 2}$ & $\mathbf{0 . 0 5 1}$ & $\mathbf{- 0 . 0 3 6}$ & $\mathbf{- 0 . 0 3 1}$ & $\mathbf{0 . 0 5 8}$ \\
$t$-statistic & $\mathbf{( 1 . 1 3 )}$ & $\mathbf{( 0 . 5 7 )}$ & $\mathbf{( 0 . 3 5 )}$ & $\mathbf{( - 0 . 2 5 )}$ & $\mathbf{( - 0 . 2 3 )}$ & $(\mathbf{0 . 5 9})$ \\
\hline Panel B & & & Size quintiles & & & \\
TAF quintiles & G1 (Small) & G2 & G3 & G4 & G5 (Large) & All stocks \\
\hline E1 (Low) & -0.648 & -0.305 & -0.008 & -0.029 & 0.047 & -0.185 \\
E2 & 0.059 & 0.028 & 0.171 & 0.022 & 0.127 & 0.082 \\
E3 & 0.278 & 0.170 & 0.057 & -0.003 & 0.010 & 0.102 \\
E4 & 0.333 & 0.183 & -0.013 & -0.067 & -0.108 & 0.063 \\
E5 (High) & 0.166 & 0.179 & -0.121 & -0.027 & -0.057 & 0.027 \\
E5 - E1 & $\mathbf{0 . 8 1 4}$-statistic & $\mathbf{0 . 4 8 4}$ & $\mathbf{- 0 . 1 1 3}$ & $\mathbf{0 . 0 0 3}$ & $\mathbf{- 0 . 1 0 5}$ & $\mathbf{0 . 2 1 2}$ \\
\hline
\end{tabular}




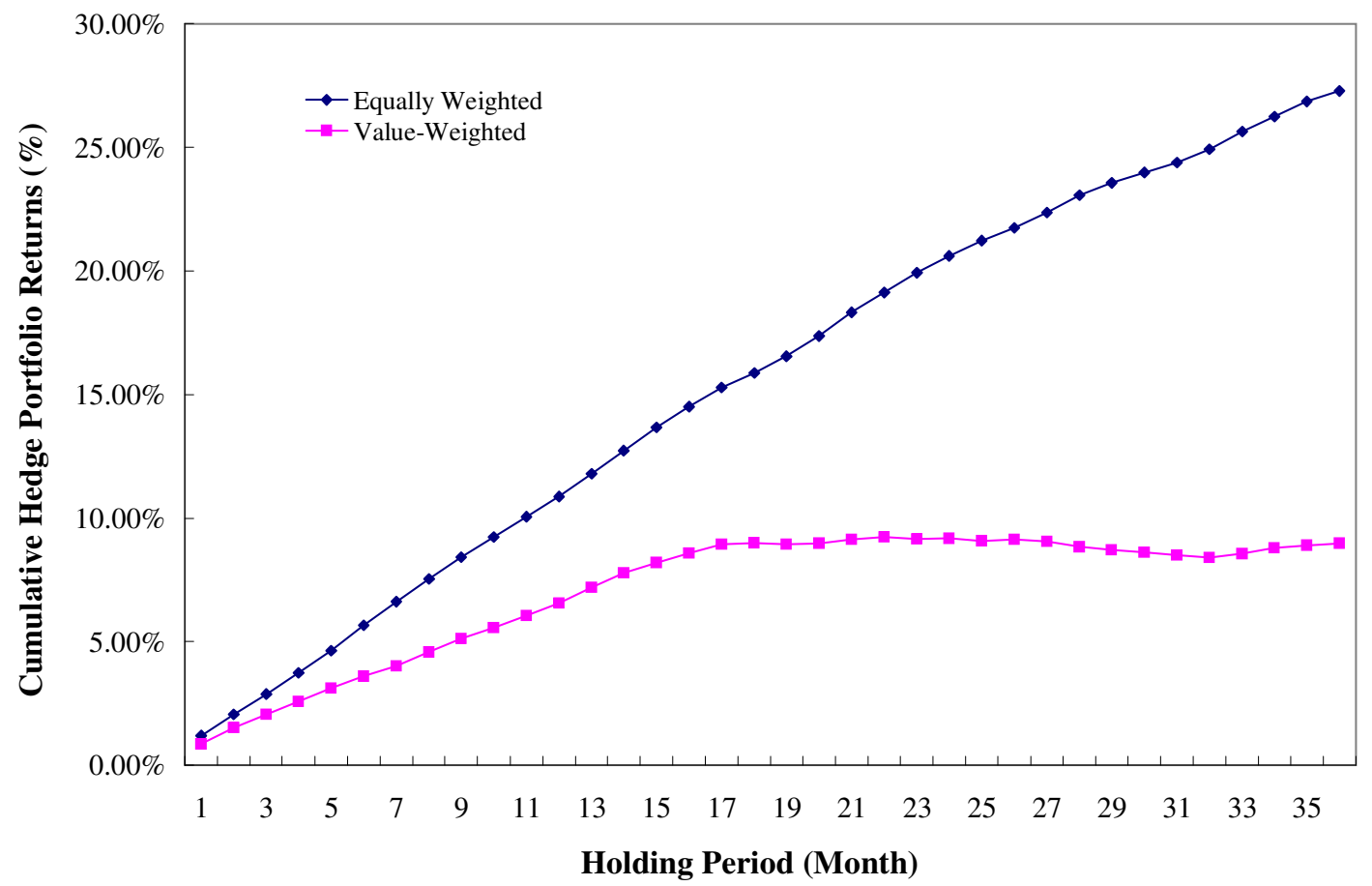

Figure 1. The cumulative (buy-and-hold) returns to a hedging strategy of buying the highest $C A F$ stocks and selling the lowest $\boldsymbol{C A F}$ stocks. At the beginning of each month from February 1983 to December 2003, all stocks are ranked into deciles based on their $C A F$ in the previous month. Ten $C A F$-sorted portfolios are formed and held for 36 months, and the portfolio returns are equal-weighted as well as value-weighted. The figure plots the difference in mean cumulative return between the highest $C A F$ decile portfolio and the lowest $C A F$ decile portfolio. 


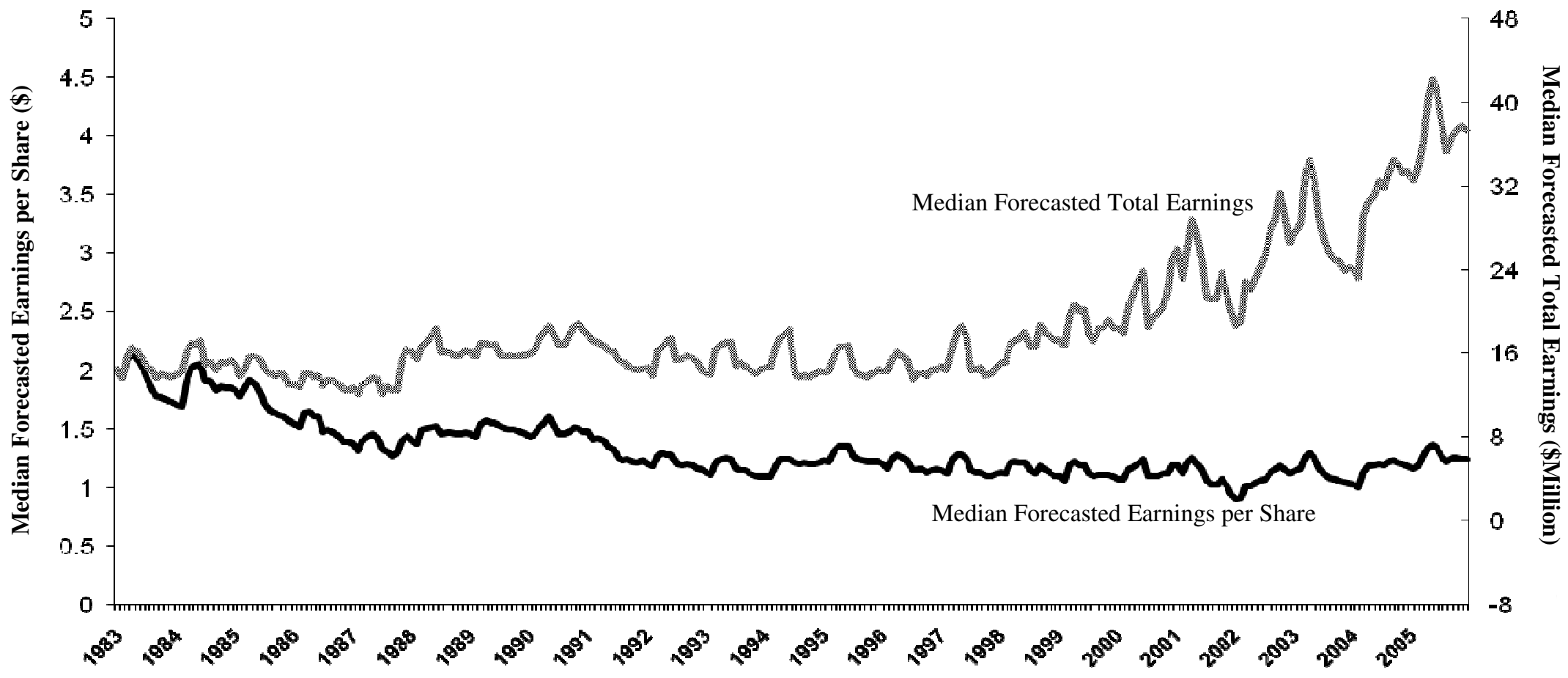

Figure 2. Median forecast earnings per share $(F-F E P S)$ and median forecast total earnings $(T F E)$ in the cross section. The solid line is the median of $F$ FEPS (\$) in the cross section and the shadowed line is the median of forecast total earnings (TFE, in million \$) from February 1983 to December 2005 . The value of TFE is presented on the right-hand side of the y-axis, while the value of F-FEPS is on the left-hand side. 